\title{
A Novel Analytic Method to Calculate the Equivalent Stray Capacitance of the Low-Speed Maglev Train's Suspension Electromagnet
}

\author{
Da Liang ${ }^{1,2, *(\mathbb{D})}$, Kunlun Zhang ${ }^{1,2, *}$, Qilong Jiang ${ }^{1, *}$ and Ying Wang ${ }^{1,2}$ \\ 1 School of Electrical Engineering, Southwest Jiaotong University, Chengdu 611756, China; \\ wangying0303@swjtu.edu.cn \\ 2 Key Laboratory of Magnetic Suspension Technology and Maglev Vehicle, Ministry of Education, \\ Southwest Jiaotong University, Chengdu 611756, China \\ * Correspondence: leungdam@my.swjtu.edu.cn (D.L.); zhangkunlun@swjtu.edu.cn (K.Z.); \\ jqlong@swjtu.edu.cn (Q.J.)
}

Received: 23 September 2020; Accepted: 15 October 2020; Published: 19 October 2020

\begin{abstract}
The suspension electromagnet (SEM) is one of the most critical components of the low-speed maglev train to achieve the stable suspension and non-contact operation with the track. Therefore, it is valuable for optimizing the maglev system to study the characteristics of the SEM. This paper proposes a novel analytic method to calculate the equivalent stray capacitance of the SEM efficiently. It considers the capacitances inside the winding (turn to turn and layer to layer) and between the winding and core. Firstly, utilizing the compensation analytic method (CAM) calculates the static capacitances to reduce the calculation error, and the results of the CAM have significant improvement comparing with that of the traditional analytic method (TAM). Secondly, the analytical formula of the core floating potential is derived based on the partial capacitance theory, which has a $2.1 \%$ relative error to the finite element method (FEM). Finally, the experiment results of the SEM of a test rig prove the accuracy and efficiency of the proposed method.
\end{abstract}

Keywords: maglev train; suspension electromagnet (SEM); floating potential; finite element method (FEM); stray capacitance

\section{Introduction}

Suspension electromagnet is one key component of the low-speed maglev train, which makes the maglev train stable, suspending through conversing electrical energy to magnetic energy $[1,2]$. Essentially, the SEM is a time-varying inductor, whose impedance would become capacitive at the natural frequency, owing to the existence of the stray capacitance [3]. The large stray capacitance would lead to the impulse current for the fast-switching occasion [4-6] and contribute to the electromagnetic interference (EMI) noise [7,8]. In Shanghai Lin'gang Maglev Test Line, a capacitance-free differential mode inductance is installed between the maglev chopper and the suspension electromagnet winding to reduce the inrush current of the chopper switches and suppress the EMI interference of the suspension controller. So far, a few pieces of literature have investigated the utilization of stray capacitance in resonant converters $[9,10]$ and EMI filter [11,12]. On the contrary, a significant amount of research has been devoted to reducing the stray capacitance by optimizing the winding's structure; preserving its inductive impedance in a high-frequency range also prevents the EMI noise $[4,13,14]$. Playing merit or avoiding malpractice, in any case, we should understand its formation mechanism and parameter extracting method firstly.

At present, the methods of extracting the stray capacitance mentioned in the literature are the measurement method $[6,15,16]$, the finite element method (FEM) $[17,18]$, and the analytic 
method [19-21]. The measurement methods are black-box techniques, which can help to obtain the equivalent stray capacitance of the suspension electromagnet but have no help to optimize the stray capacitance due to vague physical meaning. The FEM can extract the stray capacitance and is more accurate compared to the analytic methods, but it is a time-consuming method, especially for the three-dimensional FEM model. Therefore, an analytical method, which is time-saving and helpful to design and optimize the winding structure, is requisite. L. F. F. Gutierres et al. derived an analytic method for calculating stray capacitances of an air-core inductor [19], which is not suitable for the calculation of stray capacitance of the suspension electromagnet due to the existence of an iron core. Majid Ezati Mosleh et al. proposed an analytic method to calculate a slide-conductive rotor magneto cumulative generator's stray capacitance [20], which neglects the effects of the core potential on the electric field energy storage. Zhan Shen et al. [21] systematically took the influence of the iron core potential on the electric field energy into account for the first time, furthermore given several approximate methods to estimate the iron core floating potential. At the same time, Zhan Shen's team gave the equivalent circuit method [21], which is suitable for the case of including a few capacitors, whose calculation error increases with the increase in the number of the winding layers. This paper derives an analytical formula to calculate the equivalent stray capacitance of the SEM, considering the effect of the iron core on electric field energy storage. Besides, the core potential is derived utilizing the partial capacitance theory, which makes the proposed method applicable to the situation of core floating. The stray capacitance can effectively reduce by increasing the thickness of the insulation between the winding and core. Finally, the FEM numerical simulation and experiment results verify the derivation.

The rest of this paper is organized as follows. Section 2 applies the TAM and CAM, respectively, to calculate the static capacitances. Section 3 derives the analytical expressions of the iron core floating potential and the equivalent stray capacitance. In Section 4, we have utilized the FEM in different SEM models to prove the correctness and efficiency of the proposed method. Section 5 delivers the experiment results of a test rig to verify the derivation and discussion. Finally, several conclusions are drawn in Section 6.

\section{Static Capacitance Modeling}

Figure 1 presents the suspension electromagnet's structure (without the track), which mainly includes a winding and an iron core.

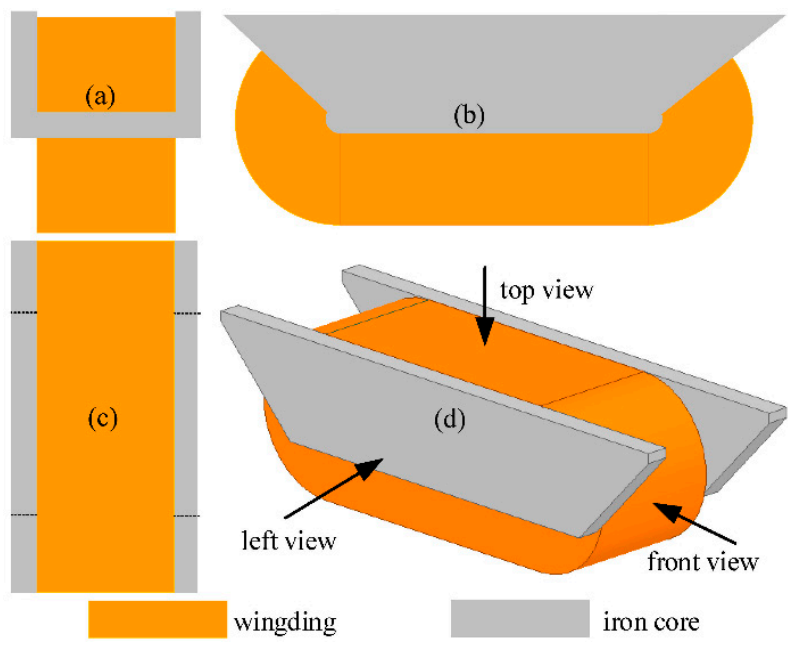

Figure 1. Structure diagram of the suspension electromagnet (without the track) of the low-speed maglev train: (a) Front view; (b) Left view; (c) Top view; (d) Three-dimensional structure.

Regarding the SEM as a multi-conductor system (MCS), the stray capacitance of SEM is the result of the potential difference between any two units (iron core and per-turn winding) in the 
MCS. The SEM winding of the low-speed maglev train is manufactured with the rectangular section wire, and the standard winding method $[9,10]$ is adopted. The capacitance is defined, which is determined by winding shape, size, space position, and insulation parameters, as the static capacitance (inherent capacitance) $[9,21]$. Figure 2 shows the winding arrangement method and the composition of static capacitances.

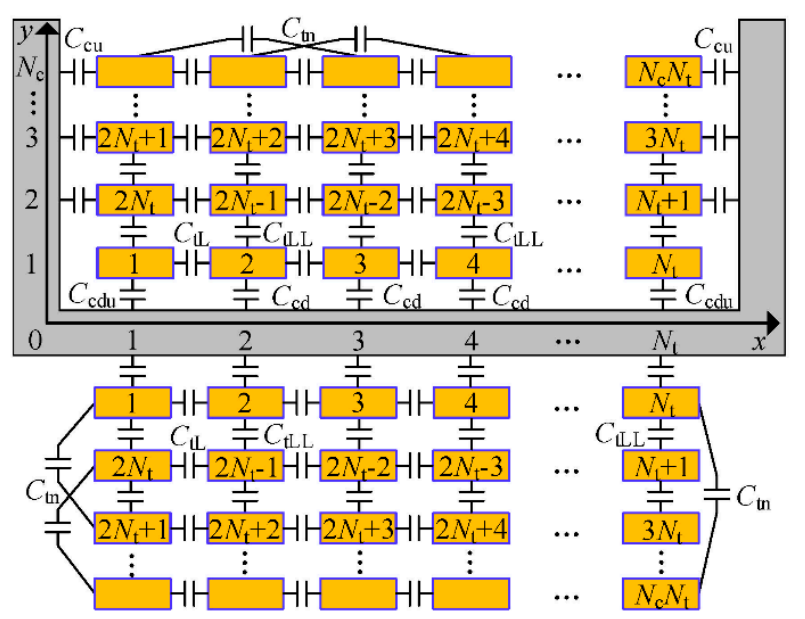

Figure 2. Static capacitances composition of the multi-conductor system of the low-speed maglev train's suspension electromagnet.

Where the $x$-axis represents the marker of the turns of the winding, the $y$-axis represents the marker of the layers of the winding. $N_{\mathrm{t}}$ is the number of turns per-layer, $N_{\mathrm{c}}$ is the number of the layers of the winding, $C_{\mathrm{tL}}$ is the static capacitance of two adjacent turns of the same layer, $C_{\mathrm{tLL}}$ is the static capacitance of two adjacent turns of different layers, $C_{\mathrm{tn}}$ is the static capacitance of non-adjacent turns. $C_{\mathrm{cd}}$ is the static capacitance between 2 th $\sim\left(N_{\mathrm{t}}-1\right)$ th turns of the first layer and the iron core, $C_{\mathrm{cu}}$ is the static capacitance between $1 \mathrm{th} / N_{\mathrm{t}}$ th of the 2 th $\sim N_{\mathrm{c}}$ th layers and the iron core, and $C_{\mathrm{cdu}}$ is the static capacitance between the $1 \mathrm{th} / \mathrm{N}_{\mathrm{t}}$ th turn of the first layer and the iron core. The equivalent stray capacitance of the winding is calculated based on electric field energy equivalence; that is, the electrical field energy stored in the equivalent capacitance is equal to that of stored in the electromagnet MCS. Therefore, the static capacitances and voltage distribution are the basis for calculating the equivalent capacitance.

\subsection{Static Capacitance Calculation by TAM}

The TAM is based on the parallel-plate capacitance model. Assuming that the winding is in order and the faceplate is smooth, it is appropriate to regard all static capacitances in the SEM as parallel-plate capacitors. The most excellent parallel-plate capacitor model is $[9,10,21]$

$$
C_{\text {eff }}=\frac{\varepsilon_{0} \varepsilon_{\text {eff }} L_{\text {eff }} w_{\text {eff }}}{d_{\text {eff }}}
$$

where $\varepsilon_{0}$ and $\varepsilon_{\text {eff }}$ are the vacuum permittivity and effective relative permittivity, respectively. $L_{\text {eff }}$ and $w_{\text {eff }}$ are the length and width of the polar plates, respectively. $d_{\text {eef }}$ is the effective distance between two plates. For the general case of three-layer insulation in series, the relative permittivity of insulation is

$$
\varepsilon_{\text {eff }}=\frac{\varepsilon_{1} \varepsilon_{2} \varepsilon_{3}\left(\delta_{1}+\delta_{2}+\delta_{3}\right)}{\varepsilon_{2} \varepsilon_{3} \delta_{1}+\varepsilon_{1} \varepsilon_{3} \delta_{2}+\varepsilon_{1} \varepsilon_{2} \delta_{3}}
$$

where $\varepsilon_{1}, \varepsilon_{2}$, and $\varepsilon_{3}\left(\delta_{1}, \delta_{2}\right.$, and $\left.\delta_{3}\right)$ are the relative permittivity (thickness) of the three series connection insulating layers. 
Figure 3 shows the relative position and dimensions of the iron core, bare wires, and insulations of the SEM.

(a)

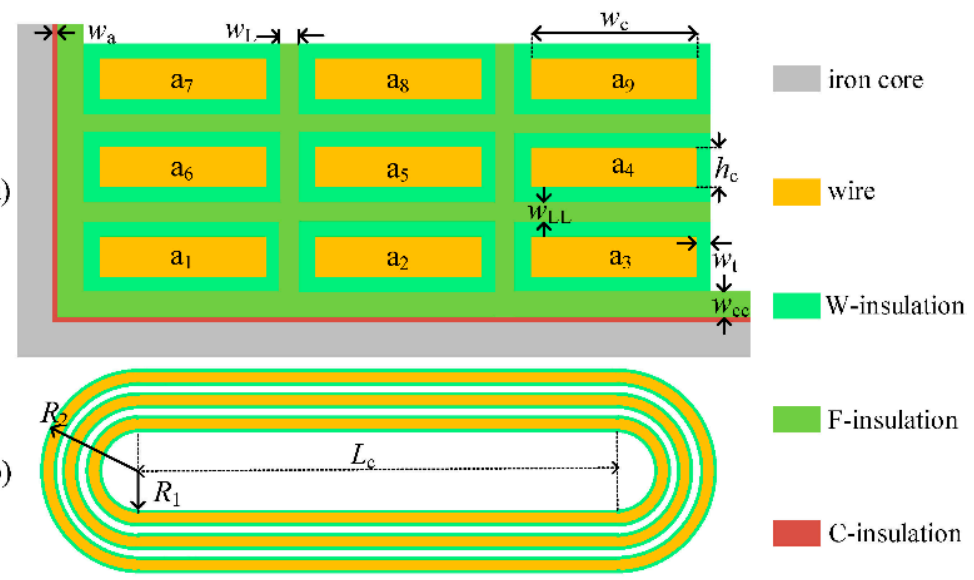

Figure 3. Geometrical relationships and dimensions among the iron core, bare wires, and insulations: (a) Perpendicular to the direction of the current; (b) Parallel to the direction of the current.

where $\mathrm{a}_{1} \sim \mathrm{a}_{9}$ are the markers of the bare wires, $w_{\mathrm{c}}$ and $h_{\mathrm{c}}$ are the width and thickness of bare wire, respectively, $w_{\mathrm{a}}$ is the thickness of iron core insulation, $w_{\mathrm{t}}$ is the thickness of conductor insulation, $w_{\mathrm{L}}$ is the thickness of filled insulation between adjacent turns of the same layer, $w_{\mathrm{LL}}$ is the thickness of insulation between adjacent turns of different layers, and $w_{\mathrm{cc}}$ is the thickness of filled insulation between the winding and the core. $R_{1}$ and $R_{2}$ are the radius of the arc part of the innermost winding and the outermost winding, respectively. $L_{\mathrm{c}}$ is the length of the linear part of the winding. Let the relative permittivity of the filled insulation (F-insulation), the wire insulation (W-insulation), and the iron core insulation (C-insulation) be $\varepsilon_{\mathrm{f}}, \varepsilon_{\mathrm{W}}$, and $\varepsilon_{\mathrm{c}}$, respectively. Combined with Figure 3 and Equation (2), the calculation parameters of $C_{\mathrm{tL}}, C_{\mathrm{tLL}}, C_{\mathrm{cd}}$, and $C_{\mathrm{cu}}$ are Equations (3)-(6), respectively.

$$
\left.\begin{array}{c}
w_{\text {eff }}=h_{\mathrm{c}}, L_{\text {eff }}=2 L_{\mathrm{c}}+\pi\left(R_{1}+R_{2}\right) \\
d_{\text {eff }}=2 w_{\mathrm{t}}+w_{\mathrm{L}}, \varepsilon_{\mathrm{eff}}=\frac{\varepsilon_{\mathrm{w}} \varepsilon_{\mathrm{f}}\left(2 w_{\mathrm{t}}+w_{\mathrm{L}}\right)}{2 \varepsilon_{\mathrm{f}} w_{\mathrm{t}}+\varepsilon_{\mathrm{w}} w_{\mathrm{L}}}
\end{array}\right\}
$$

Afterward, based on the geometrical relationship between the bare wire ag and the iron core in Figure $3 \mathrm{a}, C_{\mathrm{cdu}}$ is equivalent to that of $C_{\mathrm{cd}}$ parallel and connects with a part of $C_{\mathrm{cu}}$. Therefore, $C_{\mathrm{cdu}}$ is calculated by Equation (7).

$$
C_{\mathrm{cdu}}=C_{\mathrm{cd}}+\frac{L_{\mathrm{c}}+\pi R_{1}}{L_{\mathrm{c}}+\pi\left(R_{1}+R_{2}\right) / 2} C_{\mathrm{cu}}
$$

According to the above derivation, with the known geometrical dimensions and dielectric constant of each part insulation, we can calculate $C_{\mathrm{tL}}, C_{\mathrm{tLL}}, C_{\mathrm{cd}}$, and $C_{\mathrm{cu}}$ by substituting Equations (3)-(6) into Equation (1), respectively. Subsequently, $C_{c d u}$ is calculated by Equation (7). 


\subsection{Static Capacitance Calculation by CAM}

Compared with the TAM, the CAM compensates for the edge effect by constructing the virtual capacitor. Part 2.1 derives the TAM to calculate the static capacitances of the SEM, which ignores the influence of the edge effect. However, there are four types of special zones in the SEM shown in Figure 4. The A-type zone shown in Figure 4a is surrounded by four adjacent turns winding. The B-type zone shown in Figure $4 \mathrm{~b}$ is surrounded by two adjacent turns winding of the same layer and the iron core's side plate. The C-type zone shown in Figure 4c is surrounded by the iron core's side and bottom plates and one turn winding. The D-type zone shown in Figure $4 \mathrm{~d}$ is surrounded by two adjacent turns winding of the first layer and the iron core's bottom plate. This section considers the influence of the electric field energy stored in the zones above-mentioned to improve the calculation accuracy of the static capacitances. The specific technique is to construct the virtual capacitors in these areas to compensate for the edge effect.

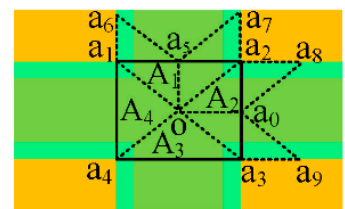

(a)

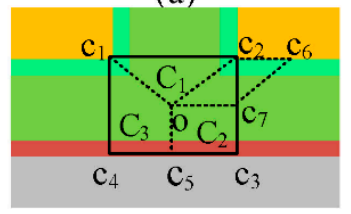

(c)

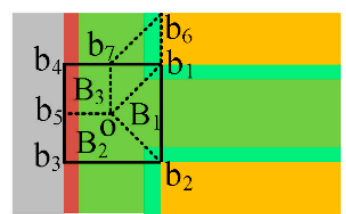

(b)

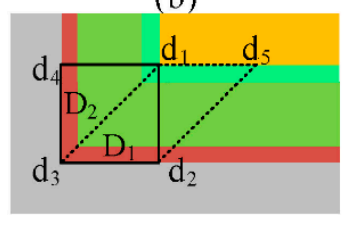

(d)

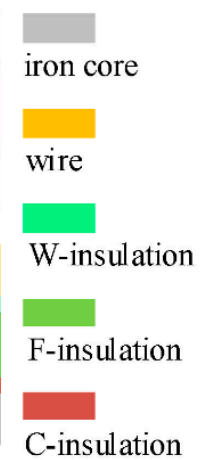

C-insulation

Figure 4. Diagram of the segmentation method of the edge effect compensation zones of the static capacitances: (a) A-type zone; (b) B-type zone; (c) C-type zone; (d) D-type zone.

The A-type zone in Figure $4 \mathrm{a}$ is divided into areas $\mathrm{A}_{1} \sim \mathrm{A}_{4}$. In $\mathrm{A}_{1}$, a virtual parallel plate capacitor is constructed, $C_{\mathrm{v}-\mathrm{tL}}$ (the subscript $\mathrm{v}$ represents the virtual capacitance, the same below), whose two pole plates are $\mathrm{a}_{1} \mathrm{a}_{6}$ and $\mathrm{a}_{2} \mathrm{a}_{7}$. The electric field line's route in $C_{\mathrm{v}-\mathrm{tL}}$ is parallel to $\left(\mathrm{a}_{1}-\mathrm{O}-\mathrm{a}_{2}\right)$. Therefore, the parameters to calculate $C_{\mathrm{v}-\mathrm{tL}}$ are

$$
\left.\begin{array}{c}
a_{1} a_{2}=2 w_{\mathrm{t}}+w_{\mathrm{L}}, a_{1} a_{4}=2 w_{\mathrm{t}}+w_{\mathrm{LL}} \\
w_{\mathrm{eff}}=\frac{a_{1} a_{4}}{2}, L_{\text {eff }}=2 L_{\mathrm{c}}+\pi\left(R_{1}+R_{2}\right) \\
d_{\mathrm{eff}}=2 \sqrt{\left(\frac{a_{1} a_{2}}{2}\right)^{2}+\left(\frac{a_{1} a_{4}}{2}\right)^{2}} \\
\varepsilon_{\text {eff }}=\frac{\varepsilon_{\mathrm{W}} \varepsilon_{\mathrm{f}}\left(2 w_{\mathrm{t}}+w_{\mathrm{L}}\right)}{2 \varepsilon_{\mathrm{f}} w_{\mathrm{t}}+\varepsilon_{\mathrm{W}} w_{\mathrm{L}}}
\end{array}\right\}
$$

Submitting Equation (8) into Equation (1), $C_{\mathrm{v}-\mathrm{tL}}$ can be obtained. By symmetry, the virtual capacitance of $A_{3}$ is the same as that of $A_{1}$. Besides, $A_{1}$ accounts for half of the virtual capacitor space, and the compensated capacitance of $C_{\mathrm{tL}}$ should include both $\mathrm{A}_{1}$ and $\mathrm{A}_{3}$ at the same time. Therefore, the static capacitance $C_{\mathrm{r}-\mathrm{tL}}$ (the subscript $\mathrm{r}$ represents the capacitance after recompensing the edge effect, the same below) is calculated by

$$
C_{\mathrm{r}-\mathrm{tL}}=\mathrm{C}_{\mathrm{tL}}+\mathrm{C}_{\mathrm{v}-\mathrm{tL}}
$$


A virtual parallel plate capacitor $\left(C_{r-t L L}\right)$, corresponding to $A_{2}$, has the plates $a_{2} a_{8}$ and $a_{3} a_{9}$, whose electric field line's route is coordinated to $\left(\mathrm{a}_{2}-\mathrm{O}-\mathrm{a}_{3}\right)$. So, the parameters to calculate $C_{\mathrm{r}-\mathrm{tLL}}$ are

$$
\left.\begin{array}{c}
a_{1} a_{2}=2 w_{\mathrm{t}}+w_{\mathrm{L}}, a_{1} a_{4}=2 w_{\mathrm{t}}+w_{\mathrm{LL}} \\
w_{\text {eff }}=\frac{a_{1} a_{2}}{2}, L_{\text {eff }}=2 L_{\mathrm{c}}+\pi\left(R_{1}+R_{2}\right) \\
d_{\text {eff }}=2 \sqrt{\left(\frac{a_{1} a_{2}}{2}\right)^{2}+\left(\frac{a_{1} a_{4}}{2}\right)^{2}} \\
\varepsilon_{\text {eff }}=\frac{\varepsilon_{\mathrm{w}} \varepsilon_{\mathrm{f}}\left(2 w_{\mathrm{t}}+w_{\mathrm{LL}}\right)}{2 \varepsilon_{\mathrm{f}} w_{\mathrm{t}}+\varepsilon_{\mathrm{w}} w_{\mathrm{LL}}}
\end{array}\right\}
$$

Submitting Equation (10) into Equation (1), $C_{\mathrm{v}-\mathrm{tLL}}$ is obtained. By symmetry, the virtual capacitance of $A_{4}$ is the same as that of $A_{2}$. In addition, $A_{2}$ accounts for half of the virtual capacitor space, and the compensated capacitance of $C_{\mathrm{tLL}}$ includes both $\mathrm{A}_{2}$ and $\mathrm{A}_{4}$ at the same time. So, $C_{\mathrm{r}-\mathrm{tLL}}$ is calculated by

$$
C_{\mathrm{r}-\mathrm{tLL}}=C_{\mathrm{tLL}}+C_{\mathrm{v}-\mathrm{tLL}}
$$

The B-type zone in Figure $4 b$ is divided into areas $B_{1} \sim B_{3}$. The compensation capacitance of $B_{1}$ is the same as that of $A_{2}$. In $A_{3}$, a virtual parallel plate capacitor is constructed, $C_{v-c u}$, whose two plates are $b_{1} b_{6}$ and $b_{4} b_{5}$, respectively. The electric field line's route in $C_{\mathrm{v}-\mathrm{cu}}$ is parallel to $\left(\mathrm{b}_{1}-\mathrm{o}-\mathrm{b}_{5}\right)$. Therefore, the parameters to calculate $C_{\mathrm{v}-\mathrm{cu}}$ are

$$
\left.\begin{array}{c}
b_{1} b_{2}=2 w_{\mathrm{t}}+w_{\mathrm{LL}}, b_{1} b_{4}=w_{\mathrm{t}}+w_{\mathrm{cc}}+w_{\mathrm{a}} \\
w_{\text {eff }}=\frac{b_{1} b_{2}}{2}, L_{\mathrm{eff}}=L_{\mathrm{c}}+\pi\left(R_{1}+R_{2}\right) \\
d_{\text {eff }}=\frac{b_{1} b_{4}}{2}+\sqrt{\left(\frac{b_{1} b_{2}}{2}\right)^{2}+\left(\frac{b_{1} b_{4}}{2}\right)^{2}} \\
\varepsilon_{\text {eff }}=\frac{\varepsilon_{c_{1} \varepsilon_{\mathrm{w}} \varepsilon_{\mathrm{f}}\left(w_{\mathrm{a}}+w_{\mathrm{c}}+w_{\mathrm{t}}\right)}^{\varepsilon_{\mathrm{f}} \varepsilon_{\mathrm{w}} w_{\mathrm{c}}+\varepsilon_{\mathrm{a}} \varepsilon_{\mathrm{w}} w_{\mathrm{cc}}+\varepsilon_{\mathrm{a}} \varepsilon_{\mathrm{f}} w_{\mathrm{t}}}}{}
\end{array}\right\}
$$

Submitting Equation (12) into Equation (1), $C_{\mathrm{v}-\mathrm{cu}}$ can be obtained. According to symmetry, the virtual capacitance of $B_{2}$ is the same as that of $B_{3}$. In addition, $A_{2}$ accounts for three-quarters of the virtual capacitor space, and the compensated capacitance of $C_{\mathrm{cu}}$ includes both $\mathrm{B}_{2}$ and $\mathrm{B}_{3}$ at the same time. So, $C_{\mathrm{r}-\mathrm{cu}}$ is calculated by

$$
C_{\mathrm{r}-\mathrm{cu}}=C_{\mathrm{cu}}+\left(3 C_{\mathrm{v}-\mathrm{cu}}\right) / 2
$$

The C-type zone in Figure $4 \mathrm{c}$ is divided into areas $C_{1} \sim C_{3}$. The compensation capacitance corresponding to $C_{1}$ is the same as that of $A_{1}$. In $C_{2}$, a virtual capacitor $C_{\mathrm{v}-\mathrm{cd}}$ is calculated, whose two plates are $c_{2} c_{6}$ and $c_{5} c_{3}$, respectively. The electric field line's route is parallel to $\left(c_{2}-\mathrm{O}-c_{5}\right)$. Therefore, the parameters to calculate $C_{\mathrm{v}-\mathrm{cd}}$ are

$$
\left.\begin{array}{c}
c_{1} c_{2}=2 w_{t}+w_{L}, c_{1} c_{4}=w_{\mathrm{t}}+w_{\mathrm{cc}}+w_{\mathrm{a}} \\
w_{\text {eff }}=\frac{c_{1} c_{2}}{2}, L_{\text {eff }}=2 L_{\mathrm{c}}+2 \pi R_{1} \\
d_{\text {eff }}=\frac{c_{1} c_{4}}{2}+\sqrt{\left(\frac{c_{1} c_{2}}{2}\right)^{2}+\left(\frac{c_{1} c_{4}}{2}\right)^{2}} \\
\varepsilon_{\text {eff }}=\frac{\varepsilon_{c} \varepsilon_{\mathrm{w}} \varepsilon_{\mathrm{f}}\left(w_{\mathrm{a}}+w_{\mathrm{cc}}+w_{\mathrm{t}}\right)}{\varepsilon_{\mathrm{f}} w_{\mathrm{w}} w_{\mathrm{c}}+\varepsilon_{\mathrm{a}} \varepsilon_{\mathrm{w}} w_{\mathrm{cc}}+\varepsilon_{\mathrm{a}} \varepsilon_{\mathrm{f}} w_{\mathrm{t}}}
\end{array}\right\}
$$

Submitting Equation (14) into Equation (1), $C_{\mathrm{v}-\mathrm{cd}}$ can be obtained. According to symmetry, the virtual capacitance of $C_{3}$ is the same as that of $C_{3}$. In addition, $C_{2}$ accounts for three-quarters of the virtual capacitor space, and the compensated capacitance of $C_{c d}$ includes both $C_{2}$ and $C_{3}$ at the same time. So, $C_{r-c d}$ is calculated by

$$
C_{\mathrm{r}-\mathrm{cd}}=C_{\mathrm{cd}}+\left(3 C_{\mathrm{v}-\mathrm{cd}}\right) / 2
$$


The D-type area in Figure $4 d$ is divided into areas $D_{1}$ and $D_{2}$. In $D_{1}$, a virtual parallel plate capacitor is constructed, $C_{v-c d u}$, whose two plates are $d_{1} d_{5}$ and $d_{3} d_{2}$. The electric field line's route in $C_{\mathrm{v}-\mathrm{cdu}}$ is coordinated to $\left(\mathrm{d}_{1}-\mathrm{d}_{3}\right)$. So, the parameters to calculate $C_{\mathrm{v}-\mathrm{cdu}}$ are

$$
\left.\begin{array}{c}
d_{1} d_{2}=d_{1} d_{4}=w_{\mathrm{t}}+w_{\mathrm{cc}}+w_{\mathrm{a}} \\
w_{\text {eff }}=d_{1} d_{4}, L_{\mathrm{eff}}=2 L_{\mathrm{c}}+2 \pi R_{1} \\
d_{\mathrm{eff}}=\sqrt{\left(d_{1} d_{2}\right)^{2}+\left(d_{1} d_{4}\right)^{2}} \\
\varepsilon_{\text {eff }}=\frac{\varepsilon_{\mathrm{c}} \varepsilon_{\mathrm{w}} \varepsilon_{\mathrm{f}}\left(w_{\mathrm{a}}+w_{\mathrm{cc}}+w_{\mathrm{t}}\right)}{\varepsilon_{\mathrm{f}} \varepsilon_{\mathrm{w}} w_{\mathrm{c}}+\varepsilon_{\mathrm{a}} \varepsilon_{\mathrm{w}} w_{\mathrm{cc}}+\varepsilon_{\mathrm{a}} \varepsilon_{\mathrm{f}} w_{\mathrm{t}}}
\end{array}\right\}
$$

Submitting Equation (16) into Equation (1), $\mathrm{C}_{\mathrm{v}-\mathrm{cdu}}$ can be obtained. Because $\mathrm{D}_{1}$ accounts for half of the virtual capacitor space, the ratio of the effective length of $D_{2}$ to that of $D_{1}$ is $\left(L_{\mathrm{c}}+\pi R_{1}\right) /\left(2 L_{\mathrm{c}}+\pi R_{1}+\pi R_{2}\right)$. In addition, the compensated capacitance of $C_{\mathrm{cd}}$ includes $\mathrm{D}_{1}, \mathrm{D}_{2}, \mathrm{~B}_{2}$, and $C_{3}$ at the same time. So, $C_{\mathrm{r}-\mathrm{cdu}}$ is calculated by

$$
C_{\mathrm{r}-\mathrm{cdu}}=C_{\mathrm{cdu}}+\left(\frac{1}{2}+\frac{1}{2} \frac{L_{\mathrm{c}}+\pi R_{1}}{2 L_{\mathrm{c}}+\pi\left(R_{1}+R_{2}\right)}\right) C_{\mathrm{v}-\mathrm{cdu}}+\frac{3}{4}\left(C_{\mathrm{v}-\mathrm{cd}}+C_{\mathrm{v}-\mathrm{cu}}\right)
$$

Through the above derivation, the static capacitances of the SEM with recompensing the edge effect are obtained by Equation (1) and Equations (8)-(17).

\section{Calculation of Electric Field Energy and Equivalent Stray Capacitance}

Section 2 of this paper calculates the static capacitances at different positions of the SEM by TAM and CAM. This section calculates the electric field energy stored in the SEM, then derives the equivalent stray capacitance based on the principle of energy storage equivalent [21-24].

\subsection{Electric Field Energy Inside the Winding}

The electric field energy inside the winding is mainly stored in the capacitances $C_{\mathrm{tL}}$ and $C_{\mathrm{tLL}}$, and the potential and potential difference distribution of the winding influence the amount of accumulation energy. The effective capacitance changes according to the charging state of the static capacitance, but the charge distribution depends on the potential distribution. For the $N_{c} \times N_{t}$ turns suspension electromagnet wingding, assuming that each turn of the winding bears the same voltage, Figure 5 gives the potential and the potential difference distribution of the winding.

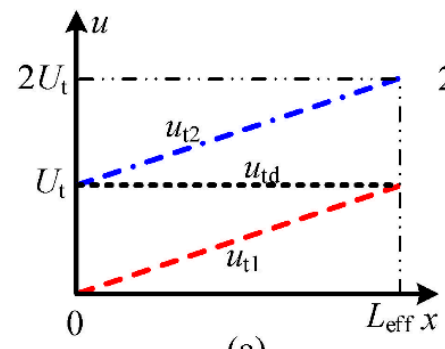

(a)

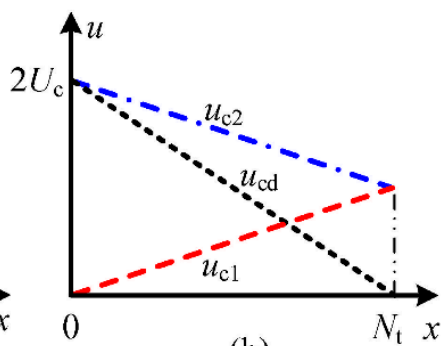

(b)

Figure 5. Potential and potential difference distribution: (a) Two adjacent turns winding. (b) Two adjacent layers winding.

In Figure $5 \mathrm{a}$, the $x$-axis is the length of the winding, $L_{\mathrm{t}}$ is the length of per turn winding, $u$-axis is the potential and potential difference, $u_{\mathrm{t} 1}$ and $u_{\mathrm{t} 2}$ are the potential distribution of the first turn winding and the second turn winding, respectively, $u_{\mathrm{td}}$ is the potential difference between $u_{\mathrm{t} 1}$ and $u_{\mathrm{t} 2}, U_{\mathrm{t}}$ is the voltage borne by per turn winding. In Figure $5 \mathrm{~b}$, the $x$-axis is the number of turns winding, the $u$-axis is the same as Figure $5 \mathrm{a}, N_{\mathrm{t}}$ is the turns number of per layer winding, $u_{\mathrm{c} 1}$ and $u_{\mathrm{c} 2}$ are the potential distribution of the first layer winding and the second layer winding, respectively, $u_{\mathrm{cd}}$ is the potential difference between $u_{\mathrm{c} 1}$ and $u_{\mathrm{c} 2}$, and $U_{\mathrm{c}}$ is the voltage borne by per layer winding. 
According to Figure $5 \mathrm{a}, \mathrm{b}$, the electric field energy stored in $C_{\mathrm{tL}}$ and $C_{\mathrm{tLL}}$ is calculated by Equations (18) and (19), respectively.

$$
\left.\begin{array}{c}
u_{\mathrm{td}}=u_{\mathrm{t} 2}-u_{\mathrm{t} 1}=U_{\mathrm{t}} \\
W_{\mathrm{tL}, \mathrm{all}}=\frac{N_{\mathrm{c}}\left(N_{\mathrm{t}}-1\right)}{2} C_{\mathrm{tL}}\left(u_{\mathrm{td}}\right)^{2}
\end{array}\right\}
$$

where $W_{\mathrm{tL}, \mathrm{all}}$ and $W_{\mathrm{tLL} \text {,all }}$ are the electric field energy stored in all $C_{\mathrm{tL}}$ and all $C_{\mathrm{tLL}}$, respectively.

\subsection{Electric Field Energy between Winding and Iron Core}

The iron core of the SEM of the low-speed maglev train is a solid-core conductor, which is insulated with the winding and surrounded by an electrostatic field produced by windings. So, the core is a floating potential conductor. With the hypothesis that the SEM winding's arrangement is according to the structure shown in Figure 2, the lowest potential of the winding is $U_{0}$, the potential difference between the first and the last turn windings is $U$, the iron core potential is $U_{\mathrm{e}}$. In case the potential distribution is from low to high, the electric field energy stored in $C_{\mathrm{cdu}}, C_{\mathrm{cd}}$, and $C_{\mathrm{cu}}$ is obtained by Equation (20).

$$
\left.\begin{array}{c}
W_{\mathrm{cdu}, \text { all }}=\frac{1}{2} C_{\mathrm{cdu}}\left[\left(U_{0}+U_{\mathrm{t}}-U_{\mathrm{e}}\right)^{2}+\left(U_{0}+N_{\mathrm{t}} U_{\mathrm{t}}-U_{\mathrm{e}}\right)^{2}\right] \\
W_{\mathrm{cd}, \mathrm{all}}=\frac{1}{2} C_{\mathrm{cd}} \sum_{k=2}^{N_{\mathrm{t}}-1}\left(U_{0}+k U_{\mathrm{t}}-U_{\mathrm{e}}\right)^{2} \\
W_{\mathrm{cu}, \text { all }}=\frac{1}{2} C_{\mathrm{cu}} \sum_{m=2}^{N_{\mathrm{c}}}\left\{\left(U_{0}+m N_{\mathrm{t}} U_{\mathrm{t}}-U_{\mathrm{e}}\right)^{2}+\left[U_{0}+\left(m N_{\mathrm{t}}-N_{\mathrm{t}}+1\right) U_{\mathrm{t}}-U_{\mathrm{e}}\right]^{2}\right\}
\end{array}\right\}
$$

where $W_{\mathrm{cdu}}$,all,$W_{\mathrm{cd}, \text { all }}$, and $W_{\mathrm{cu} \text {,all }}$ are electric energy stored in $C_{\mathrm{cdu}}, C_{\mathrm{cd}}$, and $C_{\mathrm{cu}}$, respectively. In case the potential distribution is from high to low, the electric field energy stored in $C_{\mathrm{cdu}}, C_{\mathrm{cd}}$, and $C_{\mathrm{cu}}$ is obtained by Equation (21).

$$
\left.\begin{array}{c}
W_{\mathrm{cdu}, \text { all }}=\frac{1}{2} C_{\mathrm{cdu}}\left[\left(U_{0}+U-U_{\mathrm{e}}\right)^{2}+\left(U_{0}+U-N_{\mathrm{t}} U_{\mathrm{t}}-U_{\mathrm{e}}\right)^{2}\right] \\
W_{\mathrm{cd}, \mathrm{all}}=\frac{1}{2} C_{\mathrm{cd}} \sum_{k=2}^{N_{\mathrm{t}}-1}\left(U_{0}+U-k U_{\mathrm{t}}-U_{\mathrm{e}}\right)^{2} \\
W_{\mathrm{cu}, \text { all }}=\frac{1}{2} C_{\mathrm{cu}} \sum_{m=2}^{N_{\mathrm{c}}}\left\{\left(U_{0}+U-m N_{\mathrm{t}} U_{\mathrm{t}}-U_{\mathrm{e}}\right)^{2}+\left[U_{0}+U-\left(m N_{\mathrm{t}}-N_{\mathrm{t}}+1\right) U_{\mathrm{t}}-U_{\mathrm{e}}\right]^{2}\right\}
\end{array}\right\}
$$

According to the above analysis, the electrostatic induction floating potential of the iron core should be solved firstly for calculating the electric field energy stored between the winding and the iron core. Many achievements have been achieved in the numerical solution and simulation of floating potential [25-28]. But a few pieces of literature have mentioned the analytical calculation method of floating potential. Figure 6 illustrates the relationship between the winding and the iron core potential distribution. The iron core floating potential is between $U_{1}$ and $U_{N}$ (Range 1 in Figure 6). Because the distance between the inner side winding and the iron core is closer than that of the outer side winding, $U_{\mathrm{e}}$ is limited between $U_{1}$ and $\left(U_{1}+U_{\mathrm{N}}\right) / 2$ (Range 2 in Figure 6). Consequently, an assumption is $U_{\mathrm{e}}=\left(U_{1}+U_{\mathrm{N}}\right) / 4$ (Asmp3 in Figure 6), which is suitable for approximate calculation. Furthermore, utilizing the equivalent circuit method based on KCL, Zhan Shen et al. derived the analytical formula to calculate the iron core floating potential. The iron core floating potential calculation error of the equivalent circuit method is expanding with the increase in winding layers number [21]. For example, for an 8-layers winding, the calculation error reaches $15 \%$. 


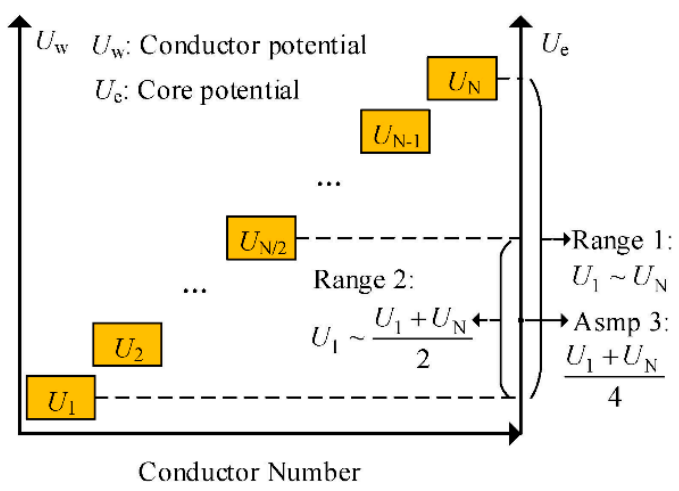

Figure 6. Relationship between winding and the iron core potential distribution.

To improve the accuracy of the floating potential calculation result, the partial capacitance theory is applied to deduce the analytical expression, which is more flexible than the equivalent circuit method.

For an $N$-conductor system, the $Q-V$ equation is written as Equation (22).

$$
\left[\begin{array}{c}
Q_{1} \\
Q_{2} \\
\vdots \\
Q_{N}
\end{array}\right]=\left[\begin{array}{cccc}
C_{11} & -C_{12} & \cdots & -C_{1 N} \\
-C_{21} & C_{22} & \cdots & -C_{2 N} \\
\vdots & \vdots & \ddots & \vdots \\
-C_{N 1} & -C_{N 2} & \cdots & C_{N N}
\end{array}\right]\left[\begin{array}{c}
v_{1} \\
v_{2} \\
\vdots \\
v_{N}
\end{array}\right]
$$

where $Q_{k}, v_{k}(k=1,2, \cdots \mathrm{N})$ are the net charge and the potential of the $k$ conductor, respectively. $C_{k k}(k=1,2 \ldots \mathrm{N})$ is the self-owned partial capacitance of the $k$ conductor, $C_{i j}(i \neq j)$ is the mutual-owned partial capacitance between the $i$ conductor and the $j$ conductor. $C_{k k}$ is calculated by Equation (23).

$$
\left\{\begin{array}{c}
C_{k k}=\sum_{i=0}^{N} f(i, k) C_{k i} \quad(k=1,2 \cdots \mathrm{N}) \\
f(i, k)= \begin{cases}1 & (\text { if } i \neq k) \\
0 & (\text { if } i=k)\end{cases}
\end{array}\right.
$$

where $C_{j 0}$ is the capacitance between the $j$ conductor and ground. Suppose that the $N$ th conductor in the conductors' system is floating potential, then $Q_{\mathrm{N}}=0$. According to Equation (23), $v_{1}, v_{2}, \cdots v_{\mathrm{N}-1}$ is used to express $v_{N}$, as shown in Equation (24).

$$
v_{N}=\frac{1}{C_{N N}} \sum_{k=1}^{N-1} C_{N k} v_{k}
$$

For the SEM, the iron core floating potential is calculated by Equation (24), with the known winding potential. The capacitances between the iron core and the adjacent conductor are much larger than the capacitances between the iron core and ground and the non-adjacent conductor. So, it is reasonable to ignore the influence of the latter to simplify the calculation. When the potential distribution of the winding is from low to high, according to Equation (24), the iron core floating potential is calculated by Equation (25).

$$
U_{\mathrm{e}}=v_{N}=U_{0}+k^{\prime} U
$$

where $k^{\prime}$ is the voltage division factor, which is calculated by Equation (26).

$$
k^{\prime}=\frac{C_{\mathrm{cdu}}\left(1+N_{\mathrm{t}}\right)+C_{\mathrm{cd}} \sum_{k=2}^{N_{\mathrm{t}}-1} k+C_{\mathrm{cu}} \sum_{j=2}^{N_{\mathrm{c}}}\left[(j-1)\left(N_{\mathrm{t}}+1\right)+j N_{\mathrm{t}}\right]}{N\left[2 C_{\mathrm{cdu}}+\left(N_{\mathrm{t}}-2\right) C_{\mathrm{cd}}+2\left(N_{c}-1\right) C_{\mathrm{cu}}\right]}
$$


When the potential distribution of the winding is from high to low, the iron core floating potential is calculated by Equation (27).

$$
U_{\mathrm{e}}=v_{N}=U_{0}+\left(1-k^{\prime}\right) U
$$

where $k^{\prime}$ is the same as Equation (25) and Equation (26). So, submitting Equation (25) into Equation (20), or Equation (27) into Equation (21), $W_{\mathrm{cdu}, \text { all }}, W_{\mathrm{cd}, \text { all }}$, and $W_{\mathrm{cu}, \text { all }}$ are obtained.

\subsection{Equivalent Stray Capacitance}

According to the principle of energy storage equivalent, Equation (31) gives the formula to calculate the equivalent stray capacitance.

$$
\left.\begin{array}{c}
C_{\mathrm{eq}}=\frac{2 W_{\mathrm{all}}}{U^{2}}=\frac{2}{U^{2}} \sum_{x} W_{x, \text { all }} \\
x=\mathrm{tL}, \mathrm{tLL}, \mathrm{cdu}, \mathrm{cd}, \mathrm{cd}
\end{array}\right\}
$$

Where $W_{\text {all }}$ is the total electric field energy stored in the SEM. Submitting Equations (18)-(21) (or Equations (18)-(21)) into Equation (28), the equivalent stray capacitance is written by Equation (29).

$$
\begin{gathered}
C_{\mathrm{eq}}=\frac{2 W_{\mathrm{all}}}{U^{2}}=k_{\mathrm{tL}} C_{\mathrm{tL}}+k_{\mathrm{tLL}} C_{\mathrm{tLL}}+k_{\mathrm{cdu}} C_{\mathrm{cdu}}+k_{\mathrm{cd}} C_{\mathrm{cd}}+k_{\mathrm{cu}} C_{\mathrm{cu}} \\
k_{\mathrm{tL}}=\frac{1}{N}-\frac{N_{\mathrm{c}}}{N^{2}}, k_{\mathrm{tLL}}=\frac{4 N\left(N_{\mathrm{c}}-1\right)}{3 N_{\mathrm{c}}^{3}}, k_{\mathrm{cdu}}=\left(\frac{1}{N}-k^{\prime}\right)^{2}+\left(\frac{N_{\mathrm{t}}}{N}-k^{\prime}\right)^{2}, \\
k_{\mathrm{cd}}=\sum_{k=2}^{N_{\mathrm{t}}-1}\left(\frac{k}{N}-k^{\prime}\right)^{2}, k_{\mathrm{cu}}=\sum_{m=2}^{N_{\mathrm{c}}}\left[\left(\frac{m N_{\mathrm{t}}-N_{\mathrm{t}}+1}{N}-k^{\prime}\right)^{2}+\left(\frac{m N_{\mathrm{t}}}{N}-k^{\prime}\right)^{2}\right]
\end{gathered}
$$

where $k_{\mathrm{tL}}, k_{\mathrm{tLL}}, k_{\mathrm{cdu}}, k_{\mathrm{cd}}$, and $k_{\mathrm{cu}}$ are the coefficients, which are determined by the inherent structure of the winding. Replacing $C_{\mathrm{tL}}, C_{\mathrm{tLL}}, C_{\mathrm{cdu}}, C_{\mathrm{cd}}$, and $C_{\mathrm{cu}}$ of Equations (18)-(29) with $C_{\mathrm{r}-\mathrm{tL}}, C_{\mathrm{r}-\mathrm{tLL}}, C_{\mathrm{r}-\mathrm{cdu}}$, $C_{\mathrm{r}-\mathrm{cd}}$, and $C_{\mathrm{r}-\mathrm{cu}}$, respectively, the parameters compensating the edge effect are obtained.

\section{Numerical Simulation and Analysis by FEM}

The FEM is an effective and accurate electromagnetic field analysis method, which is widely recognized by academics and engineering, and it can extract the capacitances of the suspension electromagnet. Two alternatives-two-dimensional (2D) and three-dimensional (3D) model of the researched object can verify the correctness of the theory and analysis. The 2D model has the advantages of simple geometric modeling, few meshes, and low computational cost; the 3D model can obtain more accurate results but with the price of a large amount of calculation and time-consuming, especially for the large size and complex model. Considering that the winding turns' number is large, and the bare conductor and insulation dimensions are very small relative to that of the iron core, the 2D finite element model is used to study the stray capacitance of the SEM. The following works are delivered to verify the correctness of the proposed analytic method: firstly, the FEM, TAM, and CAM are applied to solve the same electromagnet model, then the results obtained by three methods are compared; secondly, taking the thickness of the insulation between the iron core and winding $\left(w_{\mathrm{cc}}\right)$ as the independent variable, the applicability of TAM and CAM to different parameter conditions is studied.

\subsection{Results Comparison of the Different Methods}

The general steps of extracting the stray capacitance between two conductors by the Maxwell software are modeling geometric, assigning excitations for the conductors, solving the scalar potential, calculating the electric field strength, and computing the stray capacitance. Figure 7 shows the geometric model of the SEM. 


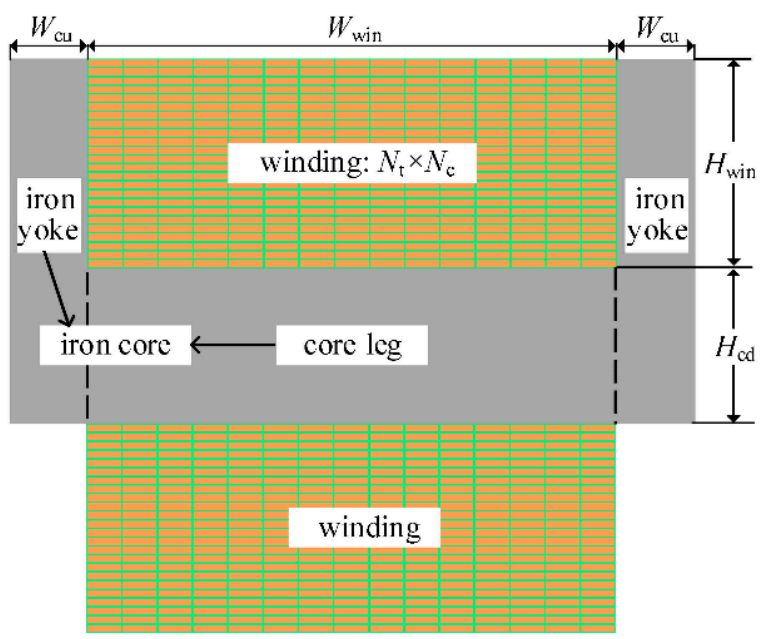

Figure 7. Outline dimensions of the suspension electromagnet of the low-speed maglev train (vertical current direction).

where $W_{\text {cu }}, H_{\text {cd }}, W_{\text {win }}$, and $H_{\text {win }}$ represent the width of the iron core, the thickness of the core leg, the width of the window, and the height of the window, respectively. The constraint relationship shown in Equation (30) should be satisfied among the dimensions' parameters of the iron core $\left(W_{\mathrm{cu}}\right.$, $H_{\mathrm{cd}}, W_{\text {win }}$, and $\left.H_{\text {win }}\right)$, winding $\left(N, N_{\mathrm{t}}\right.$, and $\left.N_{\mathrm{c}}\right)$, insulations $\left(\mathrm{w}_{\mathrm{t}}, w_{\mathrm{L}}, w_{\mathrm{LL}}, w_{\mathrm{a}}\right.$, and $\left.w_{\mathrm{cc}}\right)$, and bare wires $\left(w_{\mathrm{c}}\right.$ and $h_{\mathrm{c}}$, they are the width and the thickness of the bare wire, respectively).

$$
\left.\begin{array}{c}
N_{t} N_{c}=N \\
\left(w_{\mathrm{c}}+2 w_{\mathrm{t}}\right) N_{\mathrm{t}}+w_{\mathrm{L}}\left(N_{t}-1\right)+2\left(w_{\mathrm{a}}+w_{\mathrm{cc}}\right)=W_{\mathrm{win}} \\
\left(h_{\mathrm{c}}+2 w_{\mathrm{t}}\right) N_{c}+w_{\mathrm{LL}}\left(N_{c}-1\right)+w_{\mathrm{a}}+w_{\mathrm{cc}}=H_{\mathrm{win}}
\end{array}\right\}
$$

Table 1 gives the parameters of the SEM.

Table 1. Parameters of the FEM model of the SEM.

\begin{tabular}{cccc}
\hline Symbol & Quantity & Symbol & Quantity \\
\hline$N_{\mathrm{t}}$ & 15 & $W_{\mathrm{cu}}$ & $28 \mathrm{~mm}$ \\
$N_{\mathrm{c}}$ & 24 & $W_{\text {win }}$ & $164 \mathrm{~mm}$ \\
$w_{\mathrm{t}}$ & $0.05 \mathrm{~mm}$ & $H_{\text {win }}$ & $70 \mathrm{~mm}$ \\
$w_{\mathrm{a}}$ & $0.05 \mathrm{~mm}$ & $H_{\mathrm{cd}}$ & $58 \mathrm{~mm}$ \\
$w_{\mathrm{L}}$ & $0.2 \mathrm{~mm}$ & $\varepsilon_{0}$ & $8.85 \times 10^{-12} \mathrm{~F} / \mathrm{m}$ \\
$w_{\mathrm{LL}}$ & $0.2 \mathrm{~mm}$ & $\varepsilon_{\mathrm{a}}, \varepsilon_{\mathrm{c}}, \varepsilon_{\mathrm{f}}$ & 3.0 \\
$w_{\mathrm{cc}}$ & $0.2 \mathrm{~mm}$ & $\gamma_{\text {coil }}$ & $3.82 \times 10^{7} \mathrm{~S} / \mathrm{m}$ \\
$h_{\mathrm{c}}$ & $2.6 \mathrm{~mm}$ & $\gamma_{\text {core }}$ & $5.0 \times 10^{6} \mathrm{~S} / \mathrm{m}$ \\
$w_{\mathrm{c}}$ & $10.6 \mathrm{~mm}$ & - & - \\
\hline
\end{tabular}

Where $\gamma_{\text {coil }}$ and $\gamma_{\text {core }}$ are winding conductivity and iron core winding, respectively.

The 2D finite element model of the SEM is built with the parameters given in Table 1 . The materials of the iron core and winding are A3 steel and aluminum, respectively. The $330 \mathrm{~V}$ voltage is equally divided into 360 and is assigned to each turn according to the winding mode shown in Figure 1. The natural boundary condition and the adaptive mesh generation method are adopted.

The default depth of the Maxwell software 2D electrostatic field model is $1 \mathrm{~m}$ (cannot be modified), and the 2D model cannot deal with the arc-shaped part at both ends of the electromagnet winding. Therefore, the parameters $R_{1}=R_{2}=0$ and $L_{\mathrm{c}}=1 \mathrm{~m}$ are set to ensure the consistency between the analytical model and the finite element simulation model. Figure 8 illustrates the potential distribution of the finite element simulation of the above model. 


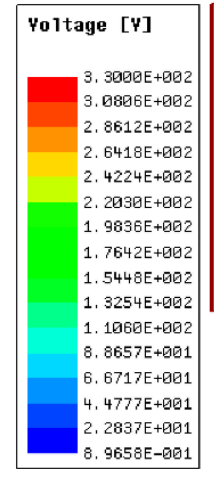

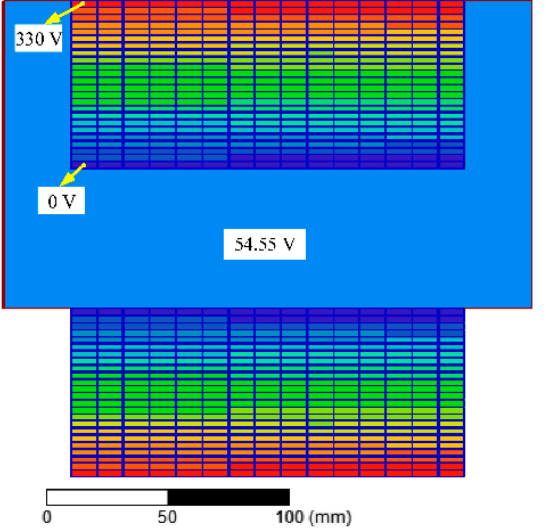

(a)
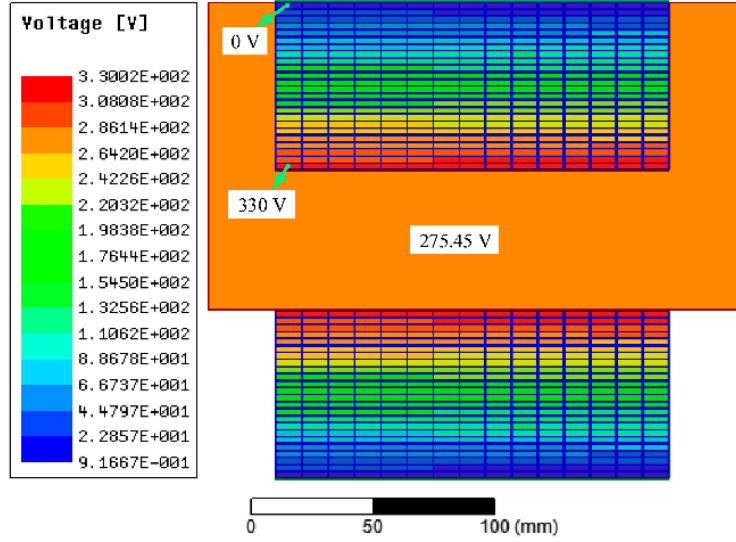

(b)

Figure 8. Potential distribution of the SEM 2D FEM model: (a) Winding potential distribution from low to high; (b) Winding potential distribution from high to low. FEM, finite element method.

In Figure 8a, the potential distribution of the winding is from low to high, and the iron core's floating potential is $54.55 \mathrm{~V}$; in Figure $8 \mathrm{~b}$, the winding's potential distribution is from high to low, and the iron core's floating potential is $275.45 \mathrm{~V}$. It proves that the relationship between Equation (25) and Equation (27) is correct. Therefore, the potential difference between the iron core and the adjacent conductors makes part of the electric field energy stored in the insulation between them, which affects the equivalent stray capacitance of the winding.

Figure 9 shows the energy density cloud chart of typical zones of the finite element simulation, in which (a), (b), (c), and (d) correspond to the A-type zone, B-type zone, C-type zone, and D-type zone mentioned in Section 2.2, respectively. There is some electric field energy in the above areas, so it is necessary to compensate for these areas when calculating the equivalent stray capacitance of the winding.
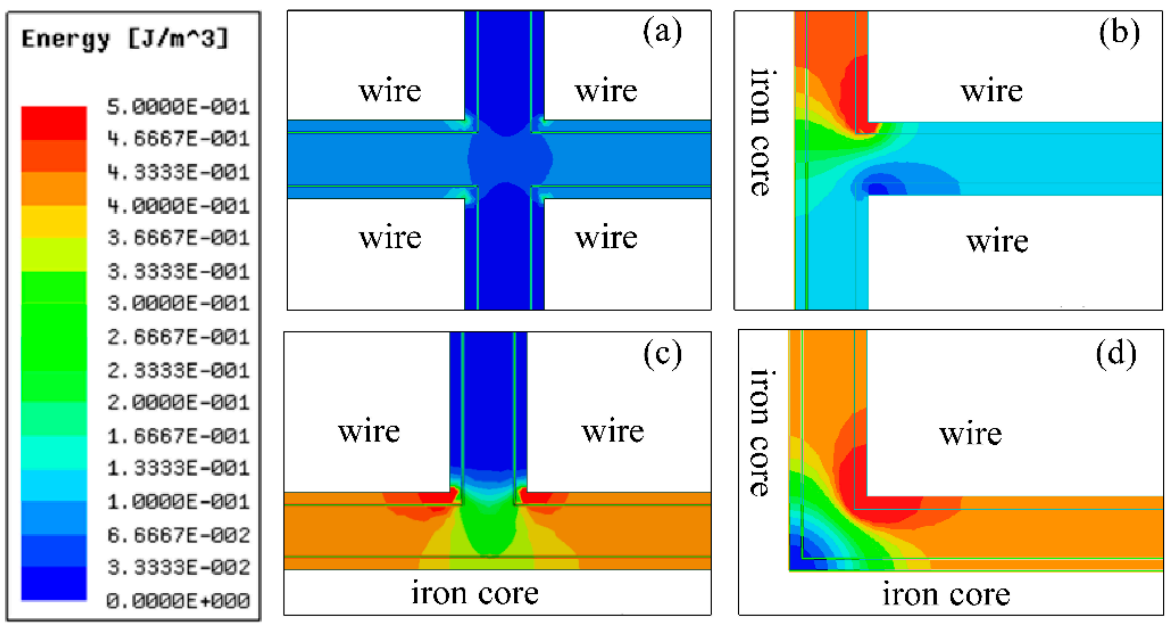

Figure 9. Energy density graph of the different edge effect compensation areas: (a) A-type zone; (b) B-type zone; (c) C-type zone; (d) D-type zone.

The calculation results of the static capacitances, the electric field energy, the equivalent stray capacitance, and the iron core's floating potential, which are by the FEM, TAM, and CAM, are given in Table 2. 
Table 2. Calculation results utilizing FEM, TAM, and CAM.

\begin{tabular}{cccc}
\hline Parameters & FEM & TAM & CAM \\
\hline$C_{\mathrm{tL}}(\mathrm{pF})$ & 478.49 & 463.0 & 481.7 \\
$C_{\mathrm{tLL}}(\mathrm{pF})$ & 1896.4 & 1879.4 & 1898.2 \\
$C_{\mathrm{cd}}(\mathrm{pF})$ & 1925 & 1879.4 & 1923.4 \\
$C_{\mathrm{cu}}(\mathrm{pF})$ & 256.58 & 231.5 & 253.6 \\
$C_{\mathrm{cdu}}(\mathrm{pF})$ & 2191.8 & 2110.9 & 2172.1 \\
$W_{\mathrm{all}}(\mu \mathrm{J})$ & 249.1 & 232.25 & 245.28 \\
$C_{\mathrm{eq}}(\mathrm{pF})$ & 4574.8 & 4265.3 & 4504.8 \\
$U_{\mathrm{e}}(\mathrm{V})$ & 54.55 & 53.40 & 55.70 \\
\hline
\end{tabular}

Figure 10 draws the relative errors (to the FEM results) bar chart of the calculation results by TAM and CAM.

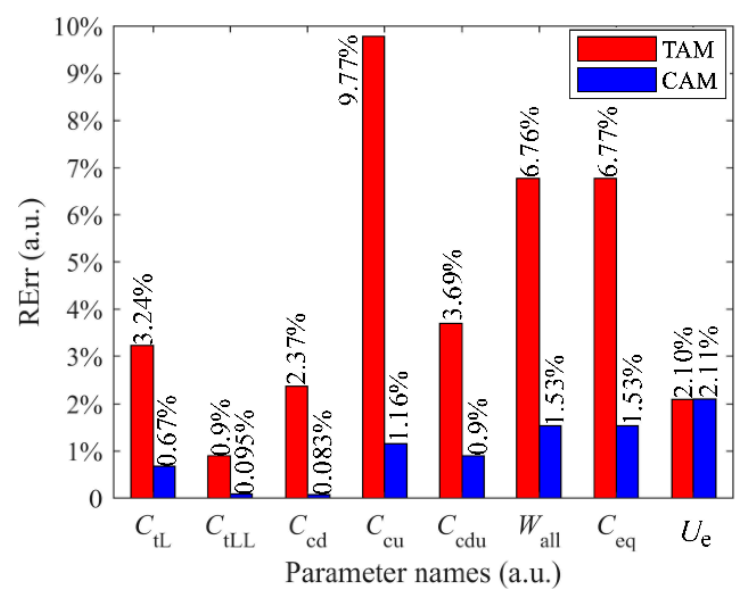

Figure 10. The relative error (to the FEM results) bar chart of the calculation results by TAM and CAM.

where RErr is the relative error and is defined as Equation (33).

$$
\text { RErr }=\frac{\left|P_{\text {TAM }}\left(P_{\text {CAM }}\right)-P_{\text {FEM }}\right|}{P_{\text {FEM }}} \times 100 \%
$$

where $P_{\mathrm{FEM}}, P_{\mathrm{TAM}}$, and $P_{\mathrm{CAM}}$ are the parameters' value calculated by the FEM, TAM, and CAM, respectively.

From Figure 10, we can know that the errors of the static capacitances, including $C_{\mathrm{tL}}, C_{\mathrm{tLL}}, C_{\mathrm{cd}}, C_{\mathrm{cu}}$, and $C_{\mathrm{cdu}}$, calculated by the CAM, are less than those of the TAM. Among them, the error of $C_{\mathrm{cu}}$ is the largest, which is caused by the smaller ratio of the plate width to the distance between plates of the corresponding parallel plate capacitor, which leads to the edge effect obvious. With the proposed edge effect compensating algorithm, the calculation error of $C_{\mathrm{cu}}$ reduces from $9.77 \%$ to $1.16 \%$, which is improved. Compared to the FEM, the relative errors of the iron core floating potential calculated by the TAM and the CAM are $2.1 \%$ and $2.11 \%$, respectively, which is caused by neglecting the capacitance between the core and non-adjacent windings (seeing the simplification of Equation (24) to Equation (25)). The errors of the equivalent stray capacitance obtained by the TAM and the CAM are $6.77 \%$ and $1.53 \%$, respectively, which are enough to meet the requirements of engineering application.

\subsection{Effects of the Insulation Thickness}

To adequately prove the validity of the proposed analytic method, different models are solved by the FEM, TAM, and CAM, respectively. Subsequently, we deliver out a comparison between different results. The dimensions of the iron core remain unchanged, and the parameters $N_{t}=15, N_{c}=24$, $w_{\mathrm{t}}=0.05 \mathrm{~mm}, w_{\mathrm{a}}=0.05 \mathrm{~mm}, w_{\mathrm{L}}=0.2 \mathrm{~mm}$, and $w_{\mathrm{LL}}=0.2 \mathrm{~mm}$ are set up. Moreover, $w_{\mathrm{cc},} w_{\mathrm{c}}$, and $h_{\mathrm{c}}$ 
change with the constraint condition of Equation (30), in which $w_{\mathrm{cc}}$ is the independent variable, $w_{\mathrm{c}}$ and $h_{\mathrm{c}}$ are dependent variables. Figure 11 gives the $w_{\mathrm{c}}-w_{\mathrm{cc}}$ and $h_{\mathrm{c}}-w_{\mathrm{cc}}$ curves, in which $w_{\mathrm{cc}}$ varies from $0.2 \mathrm{~mm}$ to $4 \mathrm{~mm}$ at intervals of $0.2 \mathrm{~mm}$.

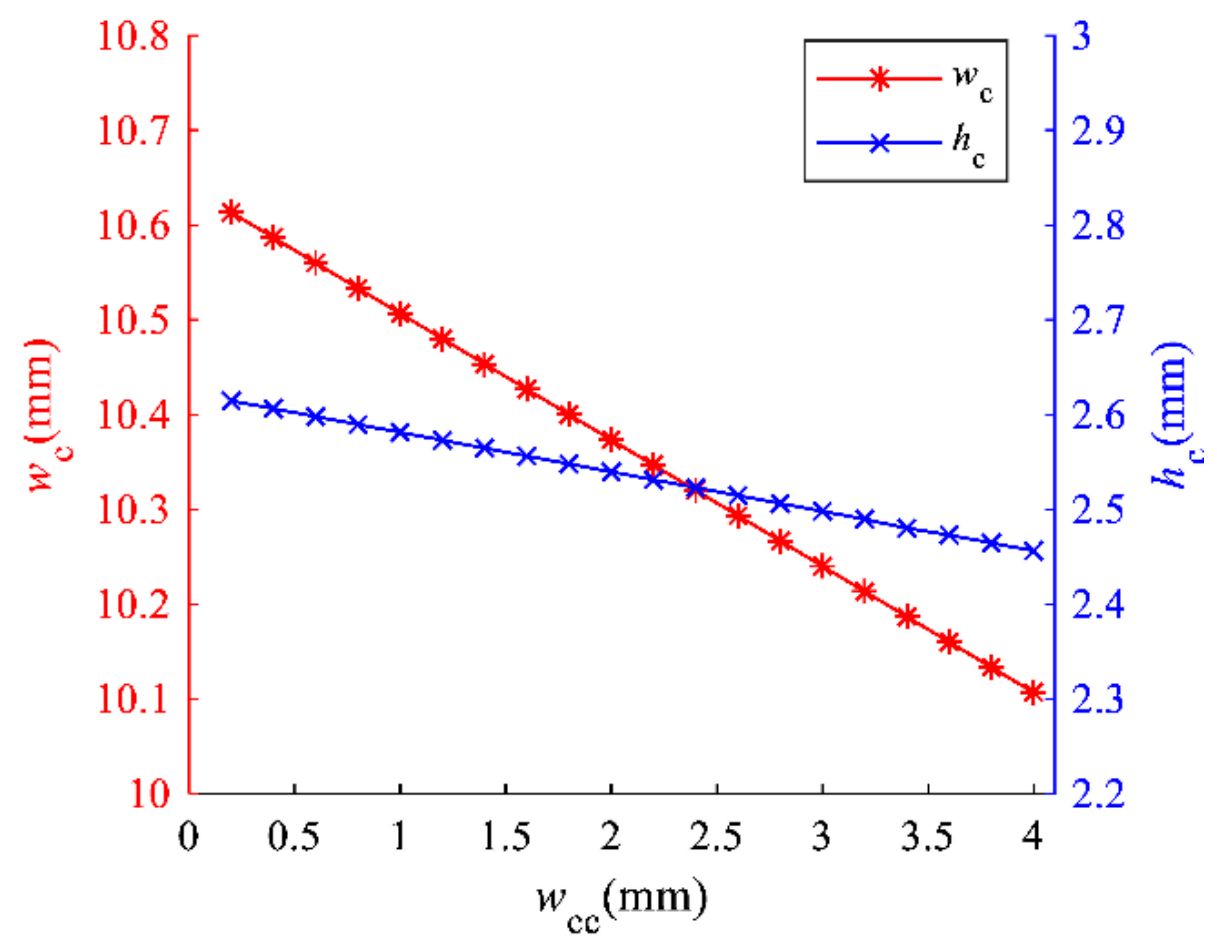

Figure 11. $w_{\mathrm{c}}-w_{\mathrm{cc}}$ and $w_{\mathrm{c}}-w_{\mathrm{cc}}$ curves.

Three methods (FEM, TAM, and CAM) are utilized to solve 20 models of the SEM (parameters are shown in Figure 11). Figure 12 shows the calculation results.

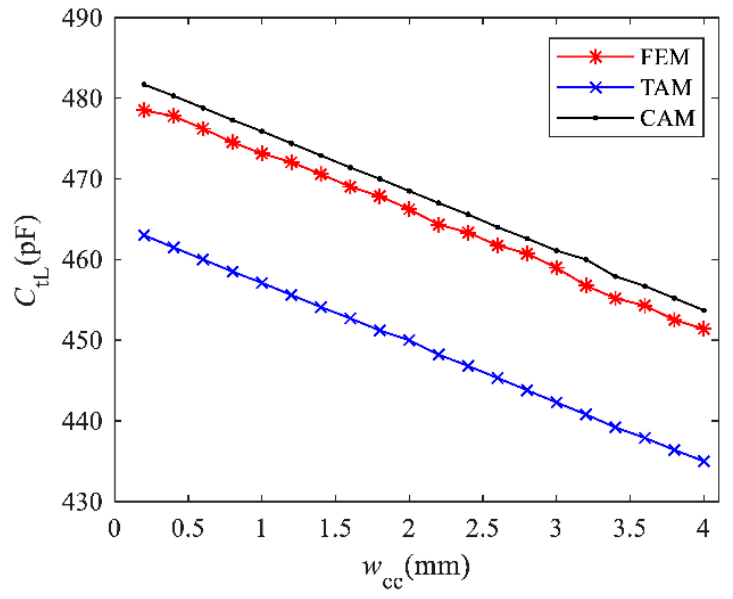

(a)

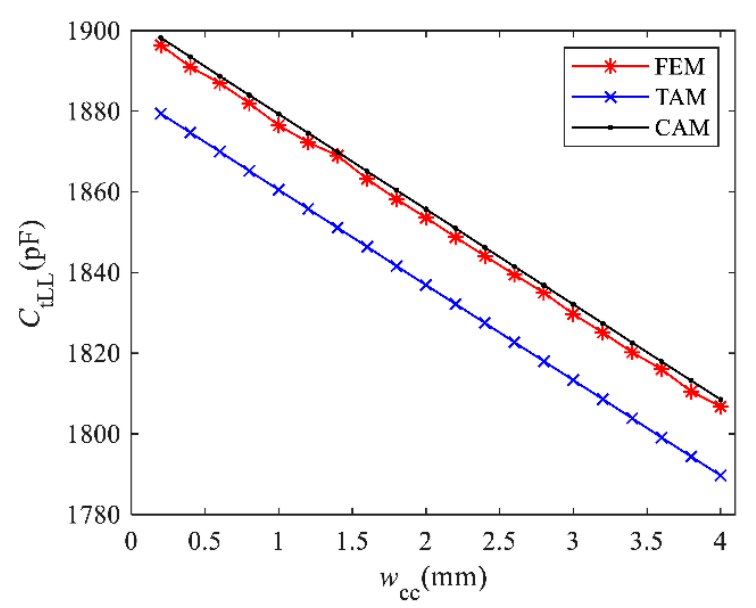

(b)

Figure 12. Cont. 


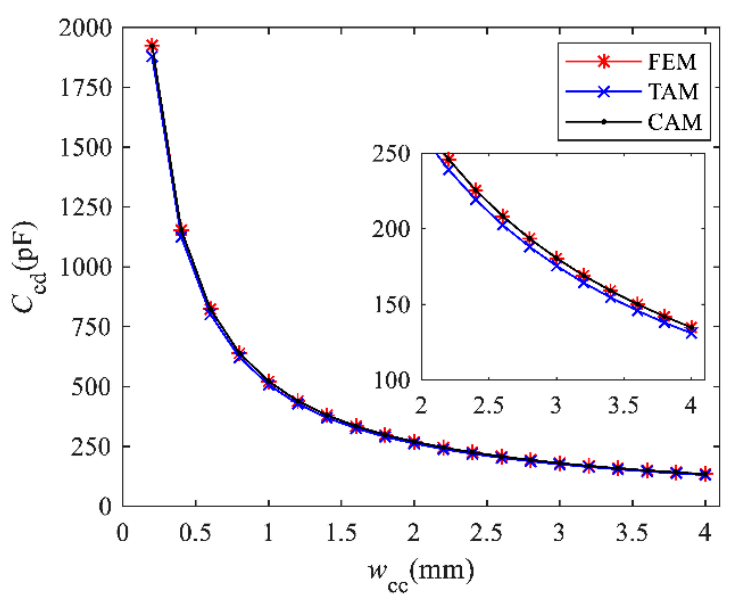

(c)

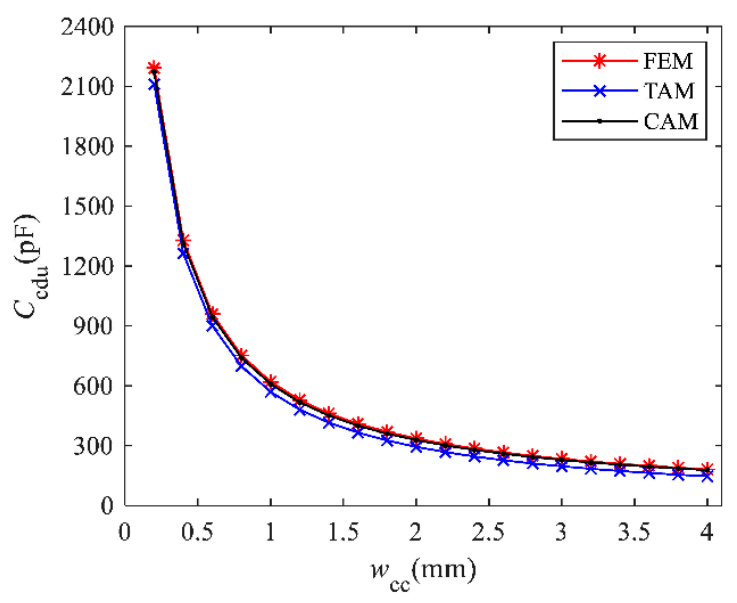

(e)

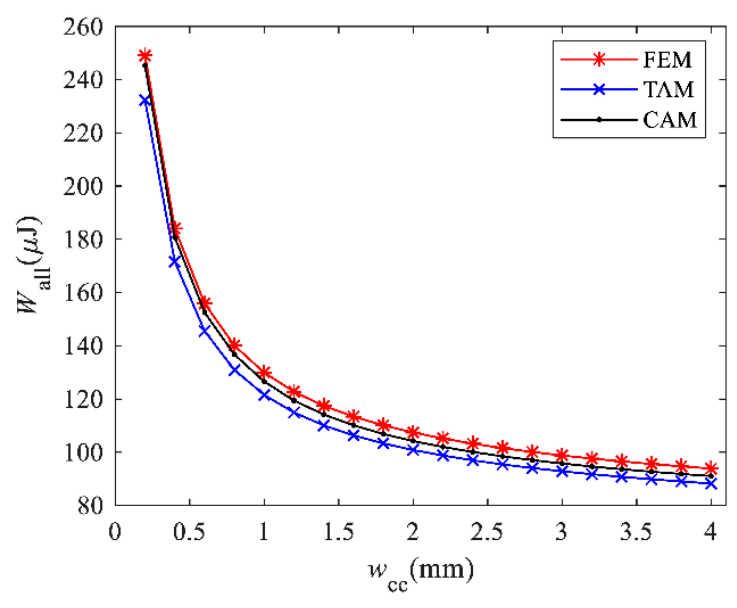

(g)

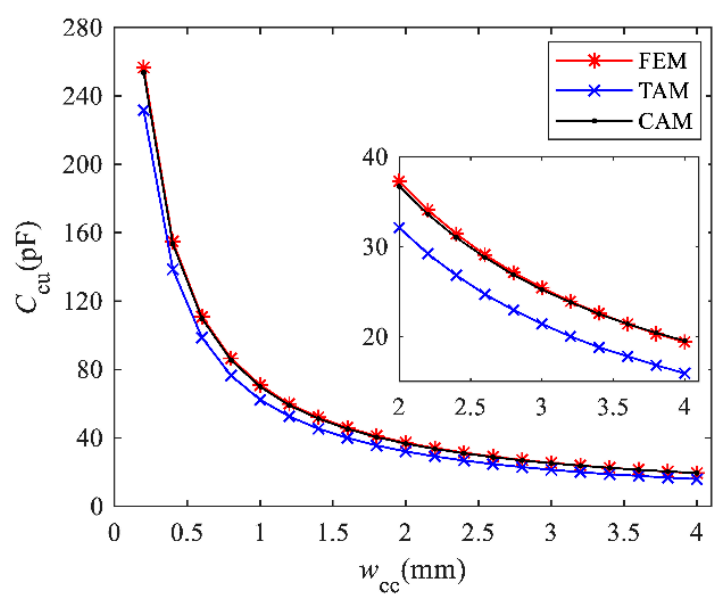

(d)

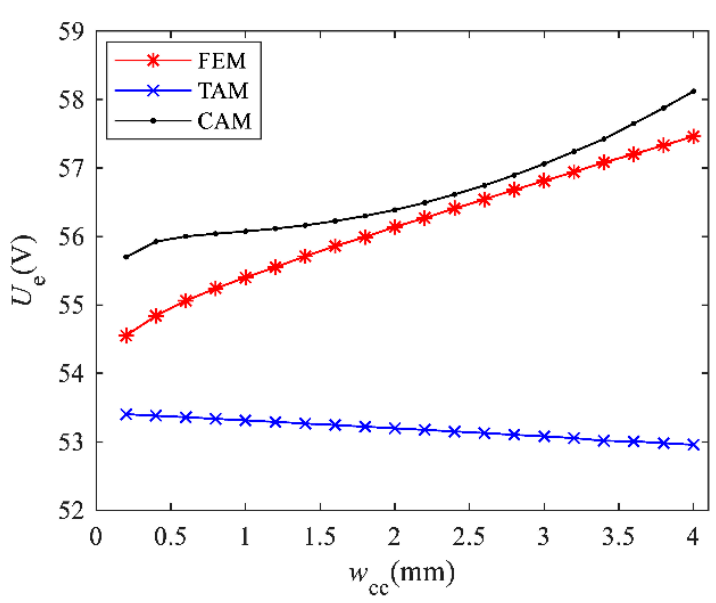

(f)

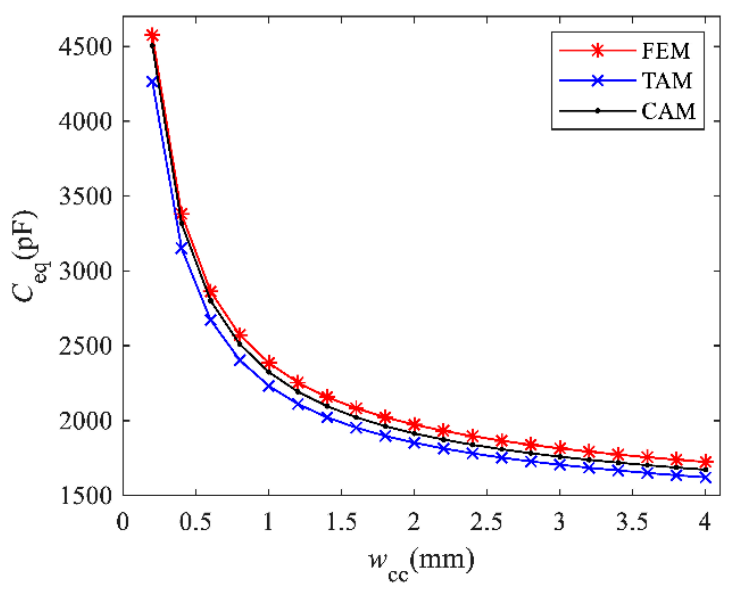

(h)

Figure 12. Comparison of the parameters obtained by FEM, TAM, and CAM: (a) static capacitance $C_{\mathrm{tL}}$; (b) static capacitance $C_{\mathrm{tLL}}$; (c) static capacitance $C_{\mathrm{cd}}$; (d) static capacitance $C_{\mathrm{cu}}$; (e) static capacitance $C_{\text {cdu }} ;(\mathbf{f})$ iron core's floating potential, $U_{\mathrm{e}} ;(\mathrm{g})$ electric field energy stored in the whole winding, $W_{\text {all }}$; (h) equivalent capacitance of the winding, $C_{\text {eq }}$. 
From Figure 12a,b, we can know that the values of $C_{\mathrm{tL}}$ and $C_{\mathrm{tLL}}$ decrease linearly with the increase in $w_{\mathrm{cc}}$, which is because $w_{\mathrm{c}}$ and $h_{\mathrm{c}}$ decrease linearly with the increase in $w_{\mathrm{cc}}$, so that the plate area of the parallel plate capacitors corresponding to $C_{\mathrm{tL}}$ and $C_{\mathrm{tLL}}$ decreases linearly. From Figure 12c-e, it is known that $C_{\mathrm{cd}}, C_{\mathrm{cu}}$, and $C_{\mathrm{cdu}}$ are inversely proportional to $w_{\mathrm{cc}}$. This is because, under the constraints of Equation (32), the area of plates and the distance between two plates of the parallel plate capacitors corresponding to $C_{\mathrm{cd}}, C_{\mathrm{cu}}$, and $C_{\mathrm{cdu}}$ are increased, and the distance between two plates is the main factor affecting the capacitance parameters. It can be seen from Figure $12 \mathrm{f}$ that $U_{\mathrm{e}}$ obtained by FEM increases with the increase in $w_{\mathrm{cc}}$, while the trend of the variation of $U_{\mathrm{e}}$ obtained by TAM is opposite to that of FEM, so the calculation error increases with the increase in $w_{\mathrm{cc}}$; the changing trend of $U_{\mathrm{e}}$ obtained by CAM is the same as that of FEM, and the maximum difference between them is less than $1.8 \mathrm{~V}$. Figure $12 \mathrm{~g}, \mathrm{~h}$ present the trend of variation of the electric field energy $W_{\text {all }}$ and the equivalent stray capacitance $C_{\mathrm{eq}}$, respectively: both of them decrease with the increase in $w_{\mathrm{cc}}$ and gradually converge to a constant. When $w_{\mathrm{cc}}$ is small, more electric field energy is stored in the insulation between the winding and iron core, and the capacitances $C_{\mathrm{cd}}, C_{\mathrm{cu}}$, and $C_{\mathrm{cdu}}$ have a significant effect on the equivalent stray capacitance; conversely, the electric field energy is mainly stored inside the winding, so the equivalent stray capacitance is mainly determined by $C_{\mathrm{tl}}$ and $C_{\mathrm{tll}}$.

With the above analysis, both TAM and CAM can solve the equivalent stray capacitance of the electromagnet winding, but the latter is more accurate. Taking the model of $w_{\mathrm{cc}}=0.2 \mathrm{~mm}$ as an example, the errors of equivalent stray capacitance calculated by TAM and CAM are $6.77 \%$ and $1.53 \%$, respectively.

\subsection{Analytic Results of the Test Rig}

Substituting the real parameters of the test rig's electromagnet $R_{1}=29 \mathrm{~mm}, R_{2}=99 \mathrm{~mm}$, $L_{\mathrm{c}}=396 \mathrm{~mm}$, and $U=330 \mathrm{~V}$ into the analytical model, the calculation results are listed in Table 3 .

Table 3. Analytical results of the test rig's SEM.

\begin{tabular}{ccc}
\hline \multirow{2}{*}{ Parameter Name } & \multicolumn{2}{c}{ Method } \\
\cline { 2 - 3 } & TAM & CAM \\
\hline $\mathrm{C}_{\mathrm{tL}}(\mathrm{pF})$ & 276.42 & 287.64 \\
$\mathrm{C}_{\mathrm{tLL}}(\mathrm{pF})$ & 1122.12 & 1133.33 \\
$\mathrm{C}_{\mathrm{cd}}(\mathrm{pF})$ & 915.47 & 936.92 \\
$\mathrm{C}_{\mathrm{cu}}(\mathrm{pF})$ & 138.21 & 155.89 \\
$\mathrm{C}_{\mathrm{cdu}}(\mathrm{pF})$ & 1028.23 & 1060.61 \\
$\mathrm{U}_{\mathrm{e}}(\mathrm{V})$ & 60.5487 & 64.1218 \\
$\mathrm{~W}_{\mathrm{all}}(\mu \mathrm{J})$ & 135.01 & 144.46 \\
$\mathrm{C}_{\mathrm{eq}}(\mathrm{pF})$ & 2479.47 & 2653.02 \\
\hline
\end{tabular}

\section{Experiments}

This section carries out experiments to verify the accuracy of the analytical model. H.Y. Lu et al. proposed the methods of measuring the stray capacitance, including the low-frequency impedance and forced resonant frequency method [22], the external series inductance resonance method, the external parallel capacitor resonance method, and the step response method. M. Zdanowski et al. introduced the frequency scanning method [5], self-oscillation excitation method, parasitic charge measurement, and the impedance analyzer method. Yet the parasitic charge method is the most effective in measuring the stray capacitance of the SEM due to the non-linearity of the iron core. This method measures the current peak during the chopper operation to calculate the equivalent stray capacitance. At the moment the transistors turn-on or turn-off, the stray capacitance is charging by the shock current, and the charge is the integration of the current waveform. 
Figure 13 gives the schematic diagram utilized to measure the equivalent stray capacitance of the SEM, where $G_{1}$ and $G_{2}$ are the field-effect transistors; $T_{1}$ and $T_{2}$ are the fast recovery diodes. $G_{1}, G_{2}$, $\mathrm{T}_{1}$, and $\mathrm{T}_{2}$ constitute the maglev chopper together.

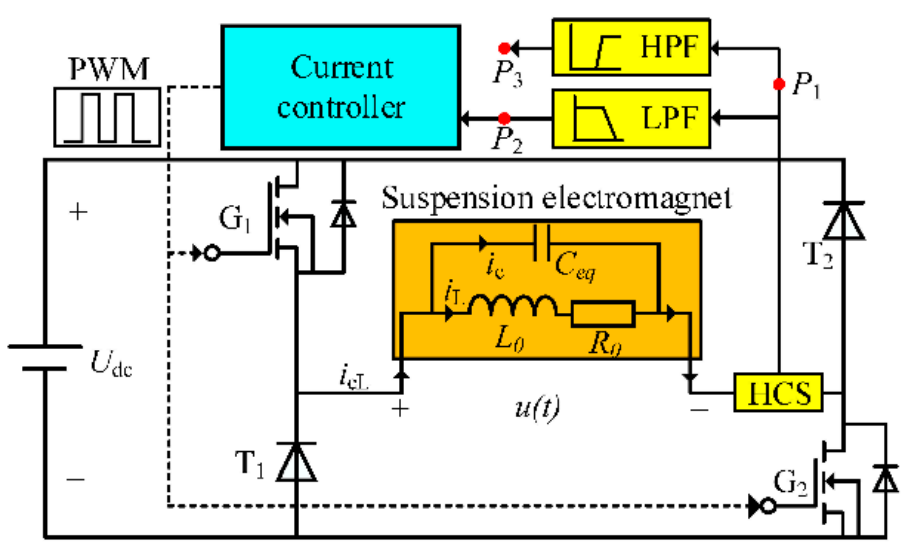

Figure 13. Schematic diagram of the experiment principle.

In Figure 13, HCS, HPF, and LPF present the hall current sensor, the high-pass filter, and the low-pass filter, respectively; $L_{0}, R_{0}$, and $C_{\text {eq }}$ are the equivalent inductance, the equivalent resistance, and the equivalent stray capacitance, respectively. $U_{\mathrm{dc}}$ is the supply voltage, $u(t)$ is the terminal voltage, $i_{\mathrm{cL}}$ is the terminal current (the current flowing the HCS), $i_{\mathrm{c}}$ is the charging current of the equivalent stray capacitance, $i_{\mathrm{L}}$ is the exciting current. $\mathrm{P}_{1}, \mathrm{P}_{2}$, and $\mathrm{P}_{3}$ are three data-acquisition points. Considering that the shock current caused by the equivalent stray capacitance occurs at the moment of switches shifting, and the duration is far less than the switching period, we design the LPF and the HPF to separate two signal components. The signal sampled from $P_{1}$ is the superposition of $i_{\mathrm{L}}$ and $i_{\mathrm{c}}$. The signals sampled from $\mathrm{P}_{1}$ and $\mathrm{P}_{3}$ are, respectively, approximate to $i_{\mathrm{L}}$ and $i_{\mathrm{c}}$.

The PI current controller is designed based on the Digital Signal Processor TMS320F28335. The supply voltage is $50 \mathrm{~V}$, the switching frequency is $10 \mathrm{kHz}$, and the target current is $10 \mathrm{~A}$. The stable current signal waveforms are shown in Figure 14.

Figure 14a shows the signal waveform of the HCS, which proves that the shock current is generated at the moment the chopper switches action. Figure 14b shows the signal waveform of the low-pass filter, in which the average current value is stable near the target current, and the ripple current amplitude is 0.05 A. Figure $14 c$,d show the signal waveform of the high-pass filter, among which Figure $14 \mathrm{~d}$ shows the current transient response waveform of once switching action. From Figure 14d, we can know that the shock current is a process of damping oscillation, and the oscillation period is 0.25 us, which is about $0.25 \%$ of the switching period. The current oscillation process completes the charging of the equivalent stray capacitance of the winding. According to the definition of capacitance, Equation (32) is obtained.

$$
C_{\mathrm{eq}}=\frac{Q}{U}=\frac{1}{U} \int i_{\mathrm{c}} d t
$$

where $Q$ is the electric charge on the plate of the capacitor, which can be obtained by time-domain integration of $i_{\mathrm{c}}$. Regarding each half period of the oscillation waveform as a triangle, Equation (32) is simplified to Equation (33).

$$
C_{\mathrm{eq}}=\frac{1}{U} \frac{1}{2} \sum_{k=1}^{4} i_{k} t_{k}
$$

where $i_{k}$ is the peak value or valley value of the current waveform. Submitting the data in Figure $14 \mathrm{~d}$ into Equation (33), the value of equivalent stray capacitance is $3 \mathrm{nF}$. The measurement result of the equivalent stray capacitance is larger $(17.35 \%$ and $11.57 \%)$ than that calculated by TAM and CAM, respectively. The reasons for the above error may be as follows: firstly, ignoring a part of the electric 
field energy stored in the electromagnet conductor system in the analytical method; secondly, due to the limitation of the manufacturing process, the analytical model is not the same from the actual model; thirdly, the measurement error in the experiment process.

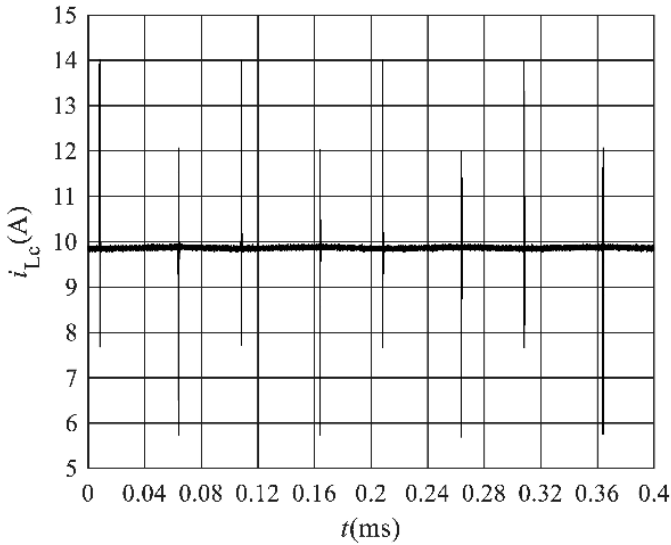

(a)

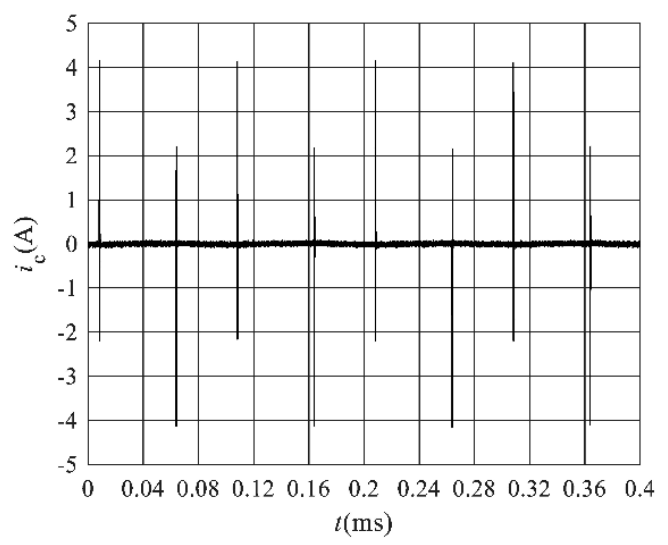

(c)

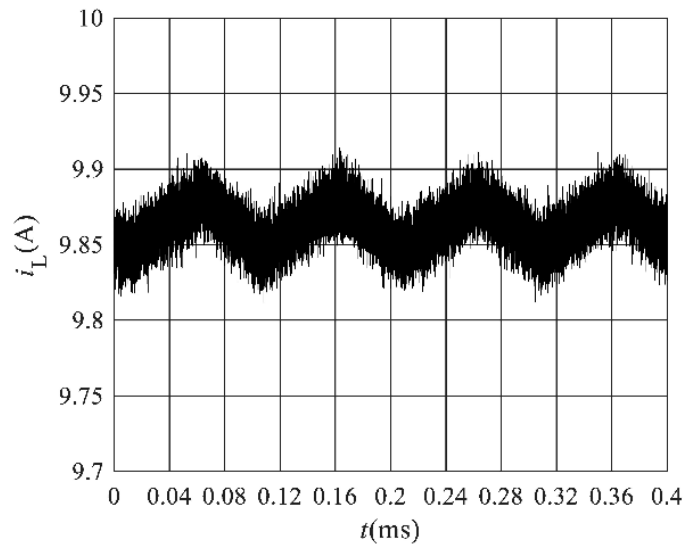

(b)

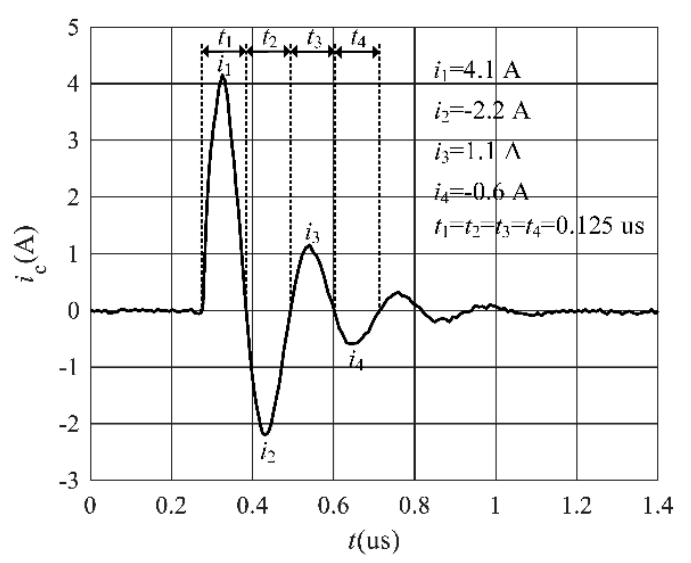

(d)

Figure 14. Current waveforms of the SEM: (a) Output signal of the hall current sensor (HCS); (b) Output signal of the low-pass filter (LPF); (c) Output signal of the high-pass filter (HPF); (d) Local enlarged of once switching action in (c).

\section{Conclusions}

This paper gives a general procedure for calculating the equivalent stray capacitance of the suspension electromagnet winding. Firstly, the TAM and CAM methods to calculate the static capacitance of suspension electromagnet winding are derived. The static capacitance parameters calculated by the CAM are closer to FEM simulation results than that of the TAM, which proves the effectiveness of the proposed edge compensation method that is based on the virtual capacitor construction. Then, according to the electrostatic field partial capacitance theory, the analytical method to calculate the floating potential of the electromagnet's iron core is derived. The error of the iron core's floating potential calculated by the TAM increases with the increase in the insulation thickness $w_{\mathrm{cc}}$ (between the winding and iron core). However, the iron core's floating potential error calculated by the CAM is less than $1.8 \mathrm{~V}$ with the variation of $w_{\mathrm{cc}}$. Finally, based on the equivalent of electric field energy storage, the analytical calculation formula of the winding port equivalent capacitance is derived. Compared with FEM simulation results, the calculation errors of TAM and CAM are, respectively, $6.77 \%$ and $1.53 \%$, and the relative error of the latter with experimental results is $11.57 \%$. Overall, the analytical method proposed in this paper quickly estimates the static capacitances of the winding, 
the floating potential of the iron core, the electrostatic field energy stored in the winding, and the equivalent capacitance of the winding port, under the conditions of known suspension electromagnet structure parameters and the winding's potential distribution. The above work provides a theoretical basis for the winding structure optimization and winding port differential mode inductance selection, which is for suppressing the EMI interference of the maglev controller.

Meanwhile, many problems still need to be solved. In the future, more works will be delivered to verify the above results. The EMI caused by the current shock, owing to the equivalent stray capacitance, needs to be further studied and measured. The optimization method of winding equivalent stray capacitance needs to be researched based on the results of this paper. Moreover, the iron core of the high-speed maglev train is composed of mutually insulated laminations. In this case, the calculation method of core potential and stray capacitance needs to be further studied.

Author Contributions: Methodology, D.L.; investigation, D.L.; writing-original draft preparation, D.L.; writing-review and editing, Q.J. and Y.W.; project administration, K.Z. All authors have read and agreed to the published version of the manuscript.

Funding: This research received no external funding.

Conflicts of Interest: The authors declare no conflict of interest.

\section{References}

1. Kim, C.H. Robust Control of Magnetic Levitation Systems Considering Disturbance Force by LSM Propulsion Systems. IEEE Trans. Magn. 2017, 53, 1-5. [CrossRef]

2. Ding, J.; Yang, X.; Long, Z.; Dang, N. Three-Dimensional Numerical Analysis and Optimization of Electromagnetic Suspension System for $200 \mathrm{~km} / \mathrm{h}$ Maglev Train Considering Eddy Current Effect. IEEE Access 2018, 6, 61547-61555. [CrossRef]

3. Zhao, H.; Li, Y.; Lin, Q.; Wang, S. The Parasitic Capacitance of Magnetic Components with Ferrite Cores Due to Time-Varying Electromagnetic (EM) Field. In Proceedings of the 2018 IEEE Energy Conversion Congress and Exposition (ECCE), Portland, OR, USA, 23-27 September 2018; pp. 3534-3541.

4. Habibinia, D.; Feyzi, M.R. Optimal winding design of a pulse transformer considering parasitic capacitance effect to reach best rise time and overshoot. IEEE Trans. Dielectr. Electr. Insul. 2014, 21, 1350-1359. [CrossRef]

5. Zdanowski, M.; Rabkowski, J.; Kostov, K.; Barlik, R.; Nee, H.P. Design and evaluation of reduced self-capacitance inductor for fast-switching SiC BJT dc/dc converters. In Proceedings of the 15th International Power Electronics and Motion Control Conference (EPE/PEMC), Novi Sad, Serbia, 4-6 September 2012; pp. DS1a.4-1-DS1a.4-7.

6. Zdanowski, M.; Kostov, K.; Rabkowski, J.; Barlik, R.; Nee, H. Design and Evaluation of Reduced Self-Capacitance Inductor in DC/DC Converters with Fast-Switching SiC Transistors. IEEE Trans. Power Electron. 2014, 29, 2492-2499. [CrossRef]

7. Wang, S.; Lee, F.C.; Chen, D.Y.; Odendaal, W.G. Effects of parasitic parameters on EMI filter performance. In Proceedings of the IEEE 34th Annual Conference on Power Electronics Specialist, Acapulco, Mexico, 15-19 June 2003; pp. 73-78.

8. Wang, S.; Lee, F.C.; Chen, D.Y.; Odendaal, W.G. Effects of parasitic parameters on EMI filter performance. IEEE Trans. Power Electron. 2004, 19, 869-877. [CrossRef]

9. Biela, J.; Kolar, J.W. Using transformer parasitics for resonant converters - a review of the calculation of the stray capacitance of transformers. In Proceedings of the Fourtieth IAS Annual Meeting. Conference Record of the 2005 Industry Applications Conference, Kowloon, Hong Kong, China, 2-6 October 2005; pp. 1868-1875. 
10. Biela, J.; Kolar, J.W. Using Transformer Parasitics for Resonant Converters-A Review of the Calculation of the Stray Capacitance of Transformers. IEEE Trans. Ind. Applicat. 2008, 44, 223-233. [CrossRef]

11. Wang, S.; Kong, P.; Lee, F.C. Common Mode Noise Reduction for Boost Converters Using General Balance Technique. IEEE Trans. Power Electron. 2007, 22, 1410-1416. [CrossRef]

12. Zhang, H.; Wang, S.; Li, Y.; Wang, Q.; Fu, D. Two-Capacitor Transformer Winding Capacitance Models for Common-Mode EMI Noise Analysis in Isolated DC-DC Converters. IEEE Trans. Power Electron. 2017, 32, 8458-8469. [CrossRef]

13. Shen, Z.; Wang, H.; Shen, Y.; Qin, Z.; Blaabjerg, F. Winding design of series AC inductor for dual active bridge converters. In Proceedings of the 2018 IEEE Applied Power Electronics Conference and Exposition (APEC), San Antonio, TX, USA, 4-8 March 2018; pp. 565-570.

14. Grandi, G.; Reggiani, U.; Kazimierczuk, M.K.; Massarini, A. Optimal Design of Single-Layer Solenoid Air-Core Inductors for High Frequency Applications. In Proceedings of the 40th Midwest Symposium on Circuits and Systems. Dedicated to the Memory of Professor Mac Van Valkenburg, Sacramento, CA, USA, 6 August 1997; pp. 358-361.

15. Liu, C.; Qi, L.; Cui, X.; Wei, X. Experimental Extraction of Parasitic Capacitances for High-Frequency Transformers. IEEE Trans. Power Electron. 2017, 32, 4157-4167. [CrossRef]

16. Naishadham, K. Extraction of RF permeability of ferrite materials using direct measurement of inductors on ferrite cores. In Proceedings of the 2011 IEEE International Symposium on Antennas and Propagation (APSURSI), Spokane, WA, USA, 3-8 July 2011; pp. 1863-1866.

17. De Grève, Z.; Deblecker, O.; Lobry, J. Numerical Modeling of Capacitive Effects in HF Multiwinding Transformers-Part I: A Rigorous Formalism Based on the Electrostatic Equations. IEEE Trans. Magn. 2013, 49, 2017-2020. [CrossRef]

18. De Grève, Z.; Deblecker, O.; Lobry, J. Numerical Modeling of Capacitive Effects in HF Multiwinding Transformers-Part II: Identification Using the Finite-Element Method. IEEE Trans. Magn. 2013, 49, 2021-2024. [CrossRef]

19. Freitas, D.F.G.; Cardoso, G. Analytical Technique for Evaluating Stray Capacitances in Multiconductor Systems: Single-Layer Air-Core Inductors. IEEE Trans. Power Electron. 2018, 33, 6147-6158. [CrossRef]

20. Mosleh, M.E.; Besmi, M.R. Stray Capacitance of a Magneto Cumulative Generator Including N-Turn, Single-Layer, Solid, and Round Conductor with Insulating Coating. IEEE Trans. Plasma Sci. 2011, 39, 1990-1997. [CrossRef]

21. Shen, Z.; Wang, H.; Shen, Y.; Qin, Z.; Blaabjerg, F. An Improved Stray Capacitance Model for Inductors. IEEE Trans. Power Electron. 2019, 34, 11153-11170. [CrossRef]

22. Lu, H.Y.; Zhu, J.G.; Ramsden, V.S.; Hui, S.Y.R. Measurement and modeling of stray capacitances in high frequency transformers. In Proceedings of the 30th Annual IEEE Power Electronics Specialists Conference. Record, Charleston, SC, USA, 1 July 1999; pp. 763-768.

23. Duerbaum, T.; Sauerlaender, G. Energy based capacitance model for magnetic devices. In Proceedings of the Sixteenth Annual IEEE Applied Power Electronics Conference and Exposition, Anaheim, CA, USA, 4-8 March 2001; pp. 109-115.

24. Kaboli, S.; Farajidavar, R. Improvement of the Energy Method for Stray Capacitance Modelling of Transformer Winding in High Voltage Power Supplies. In Proceedings of the IEEE 19th Workshop on Control and Modeling for Power Electronics (COMPEL), Padua, Italy, 25-28 June 2018; pp. 1-6.

25. Fu, W.N.; Ho, S.L.; Niu, S.; Zhu, J. Comparison Study of Finite Element Methods to Deal with Floating Conductors in Electric Field. IEEE Trans. Magn. 2012, 48, 351-354. [CrossRef]

26. Chen, L.; Dong, M.; Bagci, H. Modeling Floating Potential Conductors Using Discontinuous Galerkin Method. IEEE Access 2020, 8, 7531-7538. [CrossRef] 
27. Takuma, T.; Kawamoto, T. Numerical calculation of electric fields with a floating conductor. IEEE Trans. Dielect. Elect. Insulation 1997, 4, 177-181. [CrossRef]

28. Wenger, P.; Madhar, S.A.; Beltle, M. Simultaneous Electrical, UHF, Current and Optical PD Measurements on Floating Potential under DC Stress. In Proceedings of the 2019 IEEE Conference on Electrical Insulation and Dielectric Phenomena (CEIDP), Richland, WA, USA, 20-23 October 2019; pp. 287-290.

Publisher's Note: MDPI stays neutral with regard to jurisdictional claims in published maps and institutional affiliations.

(C) 2020 by the authors. Licensee MDPI, Basel, Switzerland. This article is an open access article distributed under the terms and conditions of the Creative Commons Attribution (CC BY) license (http://creativecommons.org/licenses/by/4.0/). 